\title{
Partner management - managing service partnerships in the supply chain - a systemic perspective
}

\author{
Uwe Zybell \\ Kuehne-Foundation Center of International Logistics Networks, \\ Technische Universitaet Berlin, Berlin, Germany
}

\begin{abstract}
Purpose - The purpose of the research is to shed light on the question of how elements of a partnership system interact to provide a basis for an enhanced performance management framework.

Design/methodology/approach - A structured literature review is followed by a longitudinal case study (action research), which combines qualitative and quantitative analyses. Observations over time, documents such as contracts, joint agreements, meeting agendas and minutes, personal conversations and in-depth interviews were mainly used, with quantitative measurement of operational and relational performance. For an in-depth analysis of interdependencies, a systemic perspective based on an interaction analysis of relevant elements of the partner management system was adopted.

Findings - The paper draws upon real-life data from service partnerships in the automotive industry. Combining a longitudinal multi-dyadic approach with action-based research makes it a unique opportunity to reveal insights into the development of performance-based partnerships. The paper illustrates enablers, limitations, and conflicting circumstances in partnering highlighting the role of incentives and derives propositions for a comprehensive framework for a performance-oriented partner management.

Research limitations/implications - Owing to the limited number of case studies, this research is considered mainly exploratory. The presented case study is an essentially illustrative example of the implementation and development of performance-oriented partnerships. The insights provide a better and deeper understanding of the dynamics of forming partnerships in reality, especially limitations and pertinent expectations regarding performance management in partnerships. There remains a need for further research for success-related dimensions and antecedents of partnering concepts in a general industry approach.

Originality/value - The paper draws upon real-life data from service partnerships in the automotive industry. Combining a longitudinal multi-dyadic approach with action-based research makes it a unique opportunity to reveal insights into the development of performance-based partnerships. The paper illustrates enablers, limitations, and conflicting circumstances in partnering highlighting the role of incentives and derives propositions for a comprehensive framework for a performance-oriented partner management.
\end{abstract}

Keywords Partnership, Performance, Incentives, Case study, Systemic thinking,

Performance management

Paper type Research paper

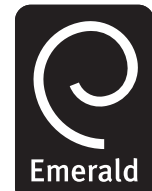

Some Enablers deserve the author's special thanks: Peter Claussen: his visionary thinking created the context which made possible this unique project. The authors' friend Dirk Stegelmeyer: his inputs in the manuscript process were continuous drivers to enhance quality. The authors' wife Verena: her partnering support was the key enabler for the successful result.

International Journal of Physical Distribution \& Logistics Management Vol. 43 No. 3, 2013 pp. $231-261$ (C) Emerald Group Publishing Limited 0960-0035

DOI 10.1108/IJPDLM-10-2011-0173

Received 17 October 2011 Revised 27 March 2012

5 June 2012

Accepted 6 June 2012

Emerald 
IJPDLM

43,3

232

\section{Introduction}

Value creation within companies has been decreasing over time and today many business activities (business processes) have been outsourced. While members and organizational units of a company have a natural incentive to improve their business processes over time because improvements benefit the organization and themselves, service providers outside the new organizational boundaries created via outsourcing may only have limited incentives for improvement (Novak and Stern, 2008) and latest research revealed that they are not very innovative (Busse, 2010). However, such improvements and adaptations are necessary for the outsourcing company to remain competitive in an ever-changing global business world.

In this domain, partnerships and especially incentives are said to be key to such sustained improvements and since the start of the 1990s, the concept of business partnerships has been attracting strong attention as a key enabler of higher performance in manufacturing companies (Ellram, 1991; Lambert et al., 1996; Mohr and Spekman, 1994; Peters, 1991). Consequently, partnership as a concept has been comprehensively discussed by academics and practitioners alike (Brennan, 1997; Langley, 2010; Lambert et al., 1996; Mentzer et al., 2000; Peters, 1991).

Despite the consensus in the literature on the high importance of partnerships, only a few studies so far have addressed the "how-to issues" (i.e. implement and manage) of partnerships in practice and criticism has emerged that neither the partnership nor the performance measurement concepts were fully understood. Meanwhile, partnership in practice had become and unfortunately remains a managerial buzzword (Fawcett et al., 2008; Lemke et al., 2003).

Over the years, researchers have adopted various perspectives to gain further insights into the partnership idea (e.g. from relationship marketing, transaction cost economics and resource based view (RBV)) (Binder and Clegg, 2007; Duffy and Fearne, 2004; Knemeyer et al., 2003). Recent research analyzing the aspects of partnership revealed that a broader set of antecedents is relevant for enabling partnering behavior (Binder and Clegg, 2007; Hofer et al.,2009). With respect to some issues of partnership, it appears that the early stages of implementing well performing business processes have become rather easy. On the contrary, improving the performance in the later stages of the relationship remains a challenge. When the full operational stage is reached, deficits remain and too little is known about how to further foster improvements (Vitasek et al., 2010; Wiendahl et al., 2005). At this stage, the perceptions and practical experiences of organizational actors are critical to gain further insights into the phenomenon. Additionally, researching this phenomenon in a real-life context seems promising and especially valuable because of the scarcity of cases that encompass the possibility to disclose the critical information needed.

The aim of this action-based research (AR) was to adopt a "standard" approach for performance-oriented partnerships, enhance the approach where shortcoming became present and understand how elements of partnerships interact in order to provide a basis for an enhanced performance management framework.

The paper covers the experiences and findings of a four-year action-based field project with a focal company and distinct partners. The picture of the emerging performance framework revealed unexpected surprises. Thus, to improve the understanding of the research results, a post hoc analysis was performed, in which interviews with service provider executives with widespread partnering expertise were conducted. This revealed further surprising insights regarding the service providers' perception of the importance 
and presence of certain elements of a partnership system. The findings are presented in five sections starting with a literature review. The subsequent methodology section presents the logic for the case design and gathering of evidence. The case observation section is organized in two subsections, starting with the implementation of a standard partnership approach, followed by the application of an enhanced, systemic perspective to a subset of partnerships. In the discussion section, the case observations and post hoc interview findings are synthesized. Finally, conclusions are drawn.

\section{Partner management}

\section{Literature review}

The literature review presents the main concepts related to the research issue. These are, first, the definition of what characterizes partnerships where we adopt a widely known definition; second, the formalization of the performance idea in partnerships, where we substantiate the above definition in one critical aspect; and finally and most important, we introduce the systemic perspective which is core to this research as it overcomes the limitations of traditional approaches in analyzing complex problems.

\subsection{Defining partnerships}

Due to recent economic development, the understanding of markets is passing through a phase of rethinking. Market mechanisms and some economic assumptions showed limitations (Akerlof and Shiller, 2009, p. xi, preface). Skepticism regarding pure markets and arms-length transaction spur the idea that partnerships can be the key in fostering the performance of manufacturing companies. Since the end of the last century, academics and practitioners alike have given strong recommendations for companies to collaborate (Lambert et al., 1996; Lemke et al., 2003; Mentzer et al., 2000; Mohr and Spekman, 1994). As a result, up to today, the term partnership more and more became a buzzword, which like other managerial fashionable expressions, is prone to overuse and consequent devaluation (Brennan, 1997). Consequently, early research sought to shed light on the partnering idea with the aim to establish a clearer understanding of the meaning of the partnership-concept. Academic and practitioner discussions reached from life-cycle aspects (Ellram, 1991) over "real-world views" (Tate, 1996) to proposals of what distinguishes transactional from partner oriented relationships (Mentzer et al., 2000), in an attempt to identify the characterizing elements of partnerships (e.g. closeness, commitment, risk-sharing). Nevertheless, the main elements that comprise a partnership still seemed not to be fully understood in these early days and very different views were held on what constitutes a partnership (Lambert et al., 1999; Lemke et al., 2003).

An often cited paper on partnering business relationships, which went beyond the mere question of "meaning", is the work of Lambert et al. (1996), which categorizes three types of partnerships depending on their character. Notwithstanding that later studies provided mixed empirical support for the existence of the three partnership types, the papers of Lambert and colleagues surpass the "meaning" discussion and by contrast suggested a definition and systematic approach for implementing partnerships (i.e. "how to do it") and therefore are helpful for developing successful partnerships (Knemeyer et al., 2003; Lambert et al., 1996, 1999, 2004). The early work of Lambert et al. (1996) also introduced an interlinked "driver"-"facilitator"-"component" process-model with outcomes and feedback elements, which later became widely adopted (Mentzer et al., 2000) and validated (Lambert et al., 2004).

This paper draws on this concept and uses the definition of partnership as: 
IJPDLM

43,3

234
[...] a tailored business relationship, based on mutual trust, openness, shared risks and shared rewards that yields a competitive advantage, resulting in business performance greater than would be achieved by the firms individually (Lambert et al., 1996, p. 2).

\subsection{Formalizing performance in partnerships}

Formalizing performance in partnerships has at least two facets, first the integration of partnership performance management in the management of the business processes and second the definition of a performance measure for the partnership. For the latter the widespread notion regarding the positive correlation between partnering and performance is a sharp contrast to the fact that a fundamental gap in the performance measuring of partnerships is acknowledged (Lambert et al., 1999) and that performance of alliances "remains one of the most exciting unexplored areas" (Gulati, 1998) - still today. This is because true synergistic interorganizational projects are rare (Fawcett et al., 2008) and the lack of appropriate measurement systems remains a major obstacle (Zimmermann and Seuring, 2009).

Traditionally, price and delivery quality have been measured to define the performance of a supplier. Following recent findings (Eggert et al., 2006; Lemke et al., 2003), high quality products, on time and for a reasonable price are no longer sufficient qualifiers for high-performing partnerships. Relationship marketing models even tend to focus on soft factors to the detriment of performance based measures (Ulaga and Eggert, 2006). Nevertheless, on the operational level, they remain the basic elements of any performance-concept (Gudehus and Kotzab, 2009, p. 3; Rodrigues et al., 2004; Stank et al., 2001; Toni and Tonchia, 2001). Following the line of thinking of this research, the investment in partnership should pay off in sustained value created during the partnership (Vitasek and Ledyard, 2009) in terms of supernormal financial benefits (Mentzer et al., 2004). Within a conceptual framework of a partnership, this consequently translates into the idea of constant improvements, which is regarded as a relevant factor of partnership success (Deepen et al., 2008; Wallenburg, 2009). This is perfectly in line with findings for buyer-supplier partnerships that new product development (i.e. improvement) is a key attribute of partnerships (Lemke et al., 2003) and with the prospect from recent market research that innovation (i.e. continuous improvement) will be a major factor in the success of relationships (Langley, 2010). So, for the purpose of this research we substantiate that "the superior performance of partnerships becomes manifest in continuous improvements achieved over the time period of the partnership".

On the level of business process management, the EFQM excellence model for management of organizations, adopted in this research, formalizes the link between partnership and continuous performance improvement. The model is among the most distinguished approaches for companies striving for excellence (Politis and Siskos, 2010). Its main characteristics can be described as follows: first, the concept provides a holistic framework to grasp the multi-dimensionality and dynamics of organizational development. Second, it posits a cause-and-effect logic with five enabler elements and four result categories. Third, learning loops provide a cyclical course of events with the aim to improve the enablers, which in turn lead to improved results (i.e. sustained superior performance) (Skarzauskiene, 2010). According to the EFQM (2011) "[e]xcellent organizations seek, develop and maintain trusting relationships with various partners to ensure mutual success [...]". Therefore, partnership is an enabler element for sustained superior performance (Figure 1). 

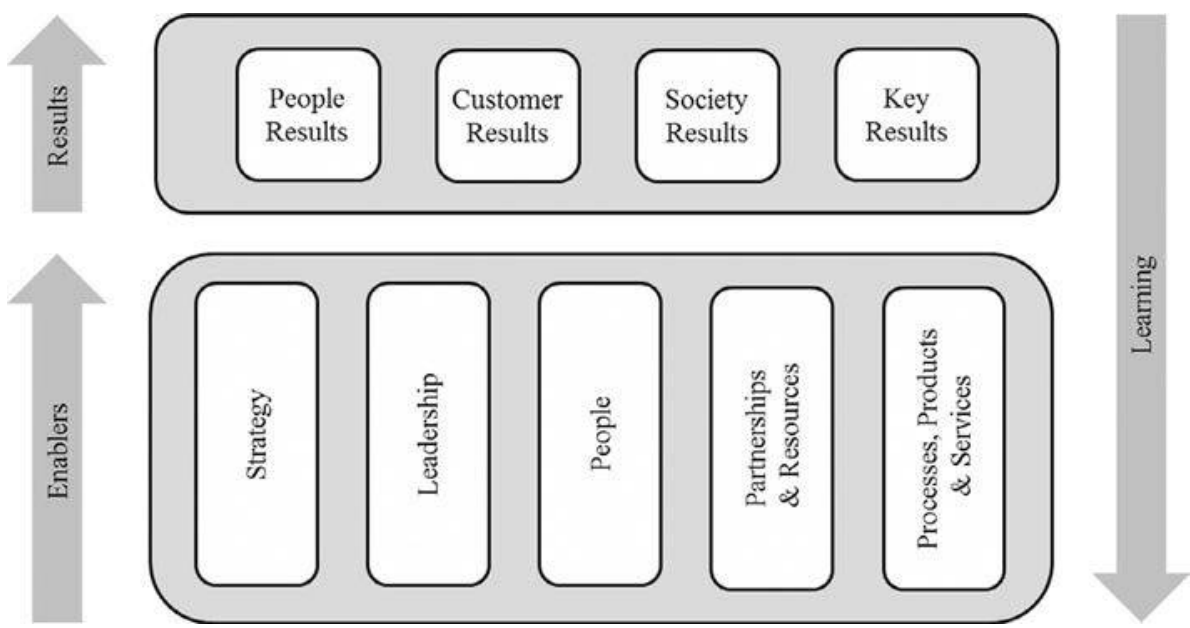

\section{Partner management}

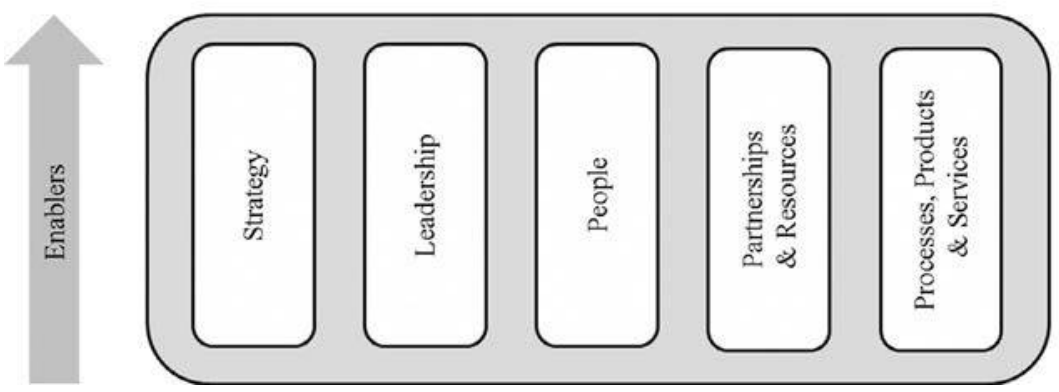

235

\subsection{Applying a systemic perspective}

The question of what drives the superior performance of partnerships and how the drivers are causally related has been researched from various theoretical perspectives. Researchers often take a pragmatic approach and combine theoretical paradigms to explain performance (Palmatier et al., 2007). In an attempt to integrate the most predominant perspectives in a single framework Palmatier et al. (2007) analyzed four theoretical perspectives resulting in a proposal to apply a RBV perspective to interfirm relationships. Most recent research empirically proposed broader frameworks for the performance oriented development of partnership by identifying relevant enablers and proposing categories for a performance framework (e.g. aligned, communicative, structured, quantified and interdependent (Richey et al., 2010)), or similarly, Information sharing and integration, people development, performance measurement, rationalization, and relationship management (Fawcett et al., 2008). Still, there is no consensus how the elements within the categories interact. To answer this question, useful contributions reflected on the fact that due to the above partnerships are complex systems, i.e. they consist of distinct elements that affect one another, forming a dynamic system. Thus, researchers' former attempts to explain unidirectional causalities of partnership performance up to today have ignored the real dynamic of partnership systems (Autry and Golicic, 2010). To overcome such limitations, this research applies a systemic thinking method which is appropriate for the analysis of complex systems, and hence has recently been become popular in the supply chain management (SCM) literature (Frankel et al., 2008; Mentzer et al., 2000).

Jointly, the EFQM model and the systemic thinking analysis posit the generic framework for this research. It reflects the systemic thinking logic and the link between partnership as an enabler and superior (partnership) performance (Figure 2).

\section{Research methodology}

Many concerns about the rigor of AR have recently been expressed (Lunnan and Haugland, 2008). This study closely follows the proposals of Yin (2009) toward a single case with multiple embedded units. Regarding the process steps for the case design, data collection, 


\section{IJPDLM \\ 43,3}

\section{6}

Figure 2.

Generic research framework
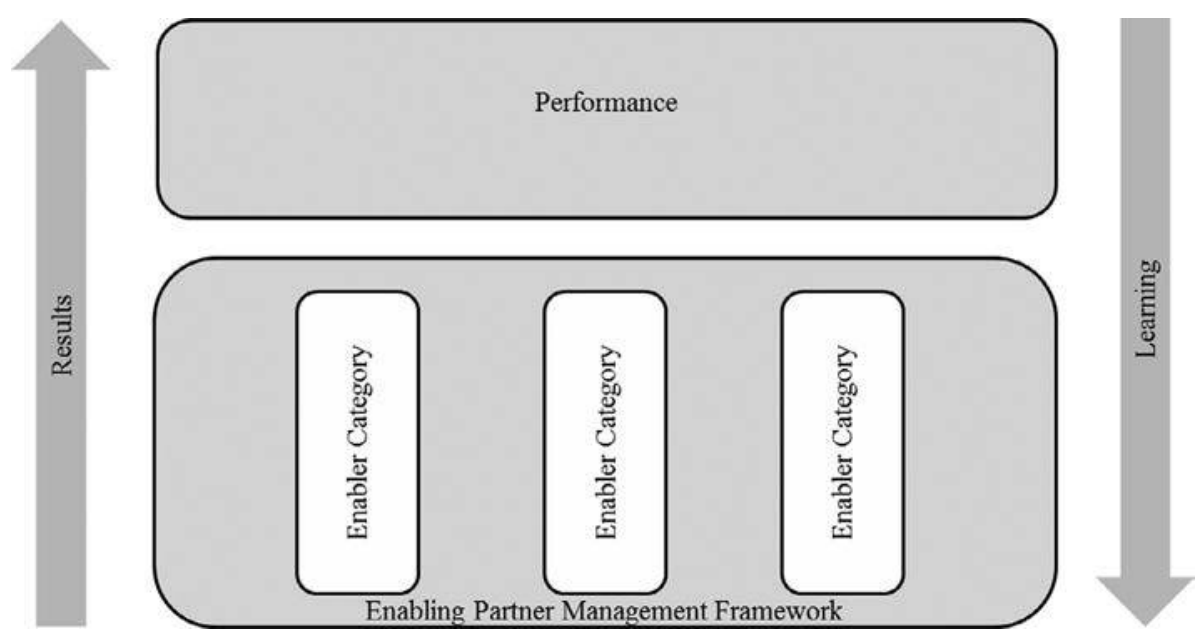

and analysis, it follows the proposal of Näslund et al. (2010) (see Appendix 1). Finally, for the analysis, the systemic thinking approach of Vester (2007) is applied.

\subsection{Case design}

The empirical evidence for this work comes from a plant and partner implementation project in the German automotive industry, where SCM is deemed to be of high significance (Zimmermann and Seuring, 2009), and therefore provides an appropriate setting to design a partnership framework and study its interdependencies with the performance of the partnership. The action research was rolled out in three stages covering a four-year period. Based on the company's EFQM model, extensive experiences and findings in literature (Lambert et al., 1996; Wiendahl et al., 2005) of how to institutionalize a partnership process, a standard partner implementation approach (see Appendix 2) was designed in stage one by the relevant departments of the focal firm; in stage two, the standard approach was applied in order to observe and pin-point potential shortcomings of such an approach. In stage three, the systemic interaction analysis was deployed to gain further insights. The study was followed up by post hoc interviews with service providers. See Figure 3 for an overview.

To establish an appropriate case logic to study the key issues under investigation the main characteristics of the case - partnership performance management and systemic perspective - have to be focused in the research approach (Barratt et al., 2011; Yin, 2009).

To address the partnership performance management issue, the company's EFQM model provides the generic enabler-result framework. Two performance measurement categories based on findings of Lambert et al. (1996) about enablers and results (components and outcomes) of partnerships were viewed: first, relational performance, which reflects the partnership-climate and comprises the elements communication, partnership, and governance; and second, operational performance, which comprises time, quality, and financial performance.

Studying a partner integration process over time enables examination of a multitude of changing aspects in the environment that make up the complex and interdependent framework within which this process of organizational change happens. Similar to the 


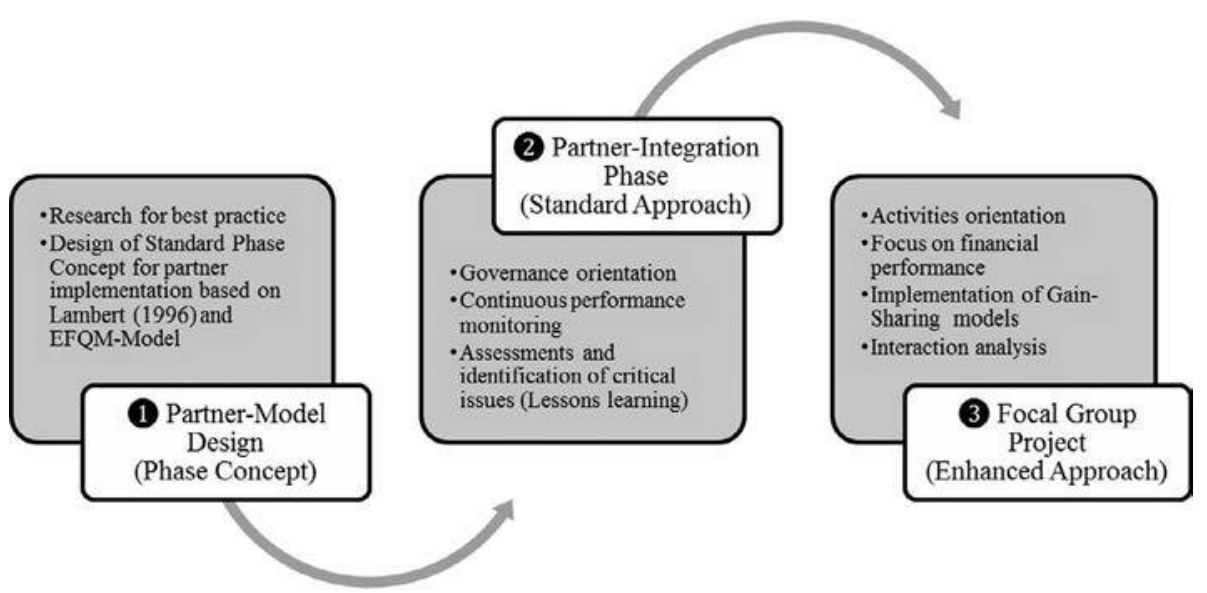

concerns regarding the rigor for case research for the analysis of complex systems, concerns frequently are expressed regarding approaches, which stipulate cause-effect relationships, overseeing that complex systems behave differently. Thus, to bypass the limiting cause-effect thinking logic inherent in the EFQM model, complementary systemic interaction analysis laid the basis for a role allocation of the key determinants of a performance oriented partnership system. The method starts with a detailed system description with the aim to identify the determinants of a complex system that are the basis for a model that reveals the systemic behavior of the system as a whole (Vester, 2007, pp. 196-205). The sensitivity analysis in the second step tries to identify the role of the system elements regarding their connectedness and their potential influence, with the aim to understand the system behavior that cannot be concluded from the analysis of each element on its own. The corresponding questions to be answered are: Which elements are control levers? Which can jeopardize the system? Which can give the system inertia?

That examination occurs with the aid of a simple matrix of influence (Vester, 2007, pp. 219-230). In the current case, 18 system elements (called variables by Vester) were identified (Section 4.2), which describe the performance oriented partnership system. The influence of one variable on every other variable is estimated by individual experts or interdisciplinary groups involved in the respective system on a scale from 0 (no influence) to 3 (strong influence). Analyzing the systemic context of the model is done based on the active sum (AS) of the variable (displayed in the rows of the matrix), which represents the sum of all outgoing effects of this one variable, and the passive sum (PS) of the variable, which represents the sum of all ingoing effects of this one variable (Figure 6). This leads to a valuation of the influence strength in a twofold way. Multiplying AS by PS characterizes each variables role in the system. The bigger that product, the greater the role, the critical character, so to say, for the system. On the other side, the AS/PS quotient reflects the active (when AS/PS > 1) or reactive (when AS/PS $<1$ ) character of each variable and denotes whether the variable is more influencing or influenced. This analysis provides a role allocation for each variable, which is particularly relevant for purposes of efficient systemic control and hence the possibility to change the system in the desired direction (Figure 4).

\section{Partner management

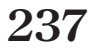

Figure 3. Holistic partner management concept for longitudinal partner-integration study 


\section{IJPDLM \\ 43,3}

\section{8}

Figure 4.

Systemic role allocation

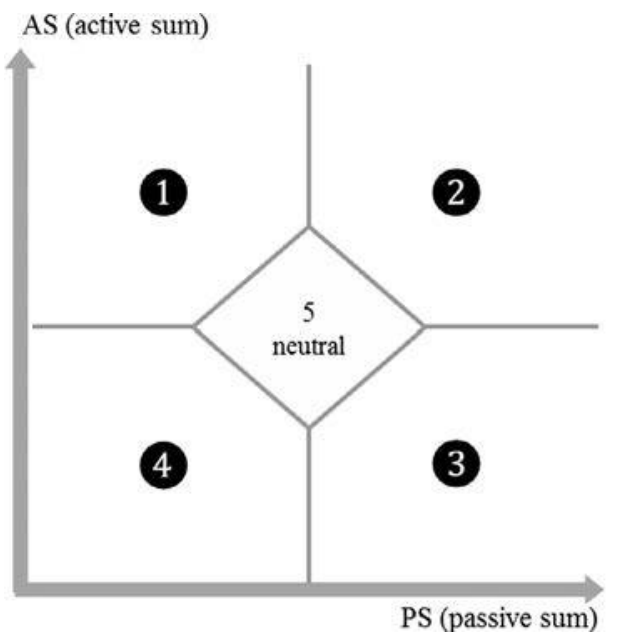

1) Control levers

that effectively stabilize the system

2) Accelerators

and catalysts suitable for firing-up in order to get things going

\section{3) Indicators}

signaling system change. Intervening to steer produces only "cosmetic" corrections

4) Buffer

Area where interventions serve no purpose

The system thinking approach shares significant similarities with the Logic Model technique, which is a useful method in case study analysis (Yin, 2009, pp. 149-154). System thinking is apt to broaden the perspective by its approach to analyzing the dynamics of relationships and understands systems as a dynamic and complex whole (Senge et al., 1999; Vester, 2007). Accordingly, central ideas of system thinking include seeing a system as a network of interlinked effects with reinforcing and balancing feedback loops leading to emergent behavior of the system as a whole. The concept is used in corporate and non-corporate applications. A very prominent one was the study assigned by the Club of Rome on the limits of growth in 1972, where the similar System Dynamics approach created by Jay W. Forrester was applied.

\subsection{Unit of analysis}

The study objects are the in-plant business relationships (partnerships) of a newly built automotive production plant with their contracted business partners. The in-plant business relationships are distinguished from external relationships by the permanent localization of business partners inside the plant. The specificities of these relationships, for example infrastructure dependency, the degree of integration in the production process of the focal company (production link) and asset specificity (Lambert et al., 1996) lead to the working hypothesis that these relationships offer the potentials of partnerships. Thus, a phase concept for implementation as outlined above and shown in Figure 3 was deemed appropriate. When shortcomings in the standard concept became apparent, in stage three an experiment (Yin, 2009, p. 8) with a focal group with the aim to gain further insights was established.

A screening of all on-site relationships revealed distinct types of relationships based on their involvement in the production process (degree of collaboration) and their potential influence on shaping the production process. Within these relationship types, the outsourced services were chosen and all 13 of the corresponding relationships viewed in this research. A further screening of these relationships revealed three distinctive sub-types. These are industrial services, logistics services, and human capital based services. The categories from the first to the latter reflect the decreasing 
level of technical skills and service specific equipment required. For the purpose of the interaction analysis, highly involved and influential relationships were of special interest. Logistics service providers qualified best for this purpose and additionally offered the advantage that regarding the critical characteristics of asset specificity and production link they are placed in the middle of the spectrum. Thus, results should more easily be transferrable to the other two groups (Table I).

\section{Partner management}

\subsection{Data collection/context of the study}

A strong point of the present $A R$ project is its continuous and unique access to multiple sources of observation, comprising internal documents from contract data to meeting minutes, insights into operational and administrative processes, etc. The dedicated full time in-plant team that rolled out the partnership project managed this process. Although employees of the plant, the team's role was to be a "cross-functional neutral instance" in the administrative and operational environment between the plant and its partners with no operational directive competencies. Consequently, the partner management unit was finally understood to be a communicative interface between the

\begin{tabular}{|c|c|c|c|c|c|c|}
\hline No. ${ }^{a}$ & Sub-type & Description & $\begin{array}{l}\text { Production } \\
\text { link }\end{array}$ & $\begin{array}{l}\text { Asset } \\
\text { specificity }\end{array}$ & $\begin{array}{l}\text { Work force } \\
\text { on-site }\end{array}$ & $\begin{array}{l}\% \text { of } \\
\text { total }\end{array}$ \\
\hline 1 & Industry service & $\begin{array}{l}\text { International provider of } \\
\text { facility management service }\end{array}$ & Medium & Low & $10-49$ & 15 \\
\hline 2 & Industry service & $\begin{array}{l}\text { Local provider of production } \\
\text { tool maintenance }\end{array}$ & Medium & Medium & $<10$ & \\
\hline 3 & Industry service & $\begin{array}{l}\text { Local provider of waste } \\
\text { disposal services }\end{array}$ & Medium & Medium & $<10$ & \\
\hline 4 & Industry service & $\begin{array}{l}\text { National provider of security } \\
\text { services }\end{array}$ & Low & Medium & $10-49$ & \\
\hline 5 & Industry service & $\begin{array}{l}\text { Regional provider of } \\
\text { maintenance services }\end{array}$ & High & Low & $10-49$ & \\
\hline 6 & Industry service & $\begin{array}{l}\text { Local provider of } \\
\text { maintenance services }\end{array}$ & Medium & High & $<10$ & \\
\hline 7 & $\begin{array}{l}\text { Logistics } \\
\text { service provider }\end{array}$ & $\begin{array}{l}\text { Regional provider of } \\
\text { outbound logistic services }\end{array}$ & Medium & Low & $10-49$ & 69 \\
\hline 8 & $\begin{array}{l}\text { Logistics } \\
\text { service provider }\end{array}$ & $\begin{array}{l}\text { International provider of } \\
\text { infrastructure management } \\
\text { and logistics services }\end{array}$ & Medium & Low & $10-49$ & \\
\hline 9 & $\begin{array}{l}\text { Logistics } \\
\text { service provider }\end{array}$ & $\begin{array}{l}\text { International provider of } \\
\text { dedicated and network based } \\
\text { logistics services }\end{array}$ & High & Low & $>50$ & \\
\hline 10 & $\begin{array}{l}\text { Logistics } \\
\text { service provider }\end{array}$ & $\begin{array}{l}\text { International provider of } \\
\text { dedicated and network based } \\
\text { logistics services }\end{array}$ & High & Medium & $>50$ & \\
\hline 11 & $\begin{array}{l}\text { Human capital } \\
\text { based service }\end{array}$ & $\begin{array}{l}\text { International provider of } \\
\text { faculty management services }\end{array}$ & Low & Low & $>50$ & 16 \\
\hline 12 & $\begin{array}{l}\text { Human capital } \\
\text { based service }\end{array}$ & $\begin{array}{l}\text { Local provider of IT-support } \\
\text { service }\end{array}$ & Low & Low & $<10$ & \\
\hline 13 & $\begin{array}{l}\text { Human capital } \\
\text { based service }\end{array}$ & $\begin{array}{l}\text { Local provider of facility } \\
\text { management services }\end{array}$ & Medium & Low & $10-49$ & \\
\hline
\end{tabular}

Note: ${ }^{a}$ Anonymized partner 
IJPDLM

43,3

240

focal company and its partners and among the in-house functions. Following Gulati (1998) this together with a clear role model is deemed to foster minimum researcher bias and influence. Therefore, the direct observations, frequent conversations, interviews, etc. of multiple investigators, which involved participants spanning from executives from numerous functions to blue collars can be supposed to reflect reliable facts and insights (Dubé and Paré, 2003; Yin, 2009, pp. 99-118).

Beyond the individual observations, a multi-dimensional approach for measuring relational (partnership-climate) and operational performance (time, quality, financial data) was used. The relational data was gathered in the form of a yearly anonymous questionnaire. This data was triangulated in post-questionnaire partner meetings. Operational data regarding time and quality were gathered based on daily ERP data and aggregated to monthly reports, which provided accurate information. For this purpose, a unified measurement approach was taken, which guaranteed uniformity and comparability across all 13 cases. Such evaluations that reflect the performance and hence the progress in partnership-development (Ariño, 2003) are an eminent characteristic of action research (Näslund et al., 2010). In contrast, for financial data individual approaches had to be agreed with partners. This on the one hand reflects the highly sensitive characteristics of this kind of information gathering, which also was only possible after having successfully established trust, ethical reputation, and the recognition of a shared interest in the initial phases of the partnership-development process. On the other hand, it reflects the aim to test different approaches, which allows for cross-case synthesis and provides the necessary flexibility for undertaking a field based AR work to improve the research results (Barratt et al., 2011; Eisenhardt, 1989; Yin, 2009). Table II illustrates the approach.

Partner meetings were held on a regular basis. The meeting scheme was part of a detailed communication structure adapted to different types of partners. During the regular partner-meetings, minutes were filed and additional field notes were recorded for all kinds of events. The partner management team comprised five members. One of the authors headed this group. Regular team meetings were held to enhance the exchange, critical reflection, and learning of the team as a whole. Such team approach is recommended to improve the quality of findings and the confidence in the results (Benbasat et al., 1987). The high integration of the partners (e.g. detailed information sharing, extensive data access) make this approach rare and fit the characteristics called for in future research (Zimmermann and Seuring, 2009).

\begin{tabular}{|c|c|c|c|c|}
\hline Category & Source & Frequency & Scale & Triangulation \\
\hline $\begin{array}{l}\text { Relational performance } \\
\text { (22 items in four } \\
\text { subcategories) }\end{array}$ & $\begin{array}{l}\text { Anonymous } \\
\text { questionnaire for local } \\
\text { management }\end{array}$ & Yearly & Traffic light logic & $\begin{array}{l}\text { Validation } \\
\text { through follow } \\
\text { up workshops }\end{array}$ \\
\hline $\begin{array}{l}\text { Tims and quality } \\
\text { performance (three to } \\
\text { four standard items) }\end{array}$ & $\begin{array}{l}\text { ERF data, automatically } \\
\text { generated }\end{array}$ & $\begin{array}{l}\text { Monthly } \\
\text { KFI report }\end{array}$ & $\begin{array}{l}\text { Traffic light logic } \\
\text { with defined } \\
\text { boundaries }\end{array}$ & $\begin{array}{l}\text { Validation in } \\
\text { regular } \\
\text { management } \\
\text { meetings }\end{array}$ \\
\hline $\begin{array}{l}\text { Financial performance } \\
\text { (individually agreed) }\end{array}$ & $\begin{array}{l}\text { ERF data, joint } \\
\text { evaluations, financial } \\
\text { figures provided by } \\
\text { partner }\end{array}$ & $\begin{array}{l}\text { Monthly } \\
\text { to } \\
\text { quarterly }\end{array}$ & $\begin{array}{l}\text { Service levels, } \\
\text { scope of service, } \\
\text { performance } \\
\text { figures }\end{array}$ & $\begin{array}{l}\text { ERP data, joint } \\
\text { evaluations, } \\
\text { plausibility } \\
\text { checks }\end{array}$ \\
\hline
\end{tabular}

Table II.

Performance

measurement approach 


\section{Case observations}

\subsection{Stages 1 and 2 (preliminary results derived from partner implementation)}

Following the theoretical propositions of how to set-up partnerships, the previously mentioned systematic partner implementation approach (Appendix 2) should (constantly) generate benefits in relational and operational performance (Hofer et al., 2009; Zacharia et al., 2009). After a period of 24 months, passing through the early stage of the partnerships implementation until reaching full production capacity and process complexity, the following conclusions regarding the performance data in the sample of 13 partners could be drawn.

Across the whole sample the relational performance constantly rose in the shape of a logarithmical function. Given the absolute high values that were reached at the end of the 24-month period, this could be interpreted as a sign of saturation on a high level.

The operational performance with regard to time and quality also rose in a flattening curve and reached a "ceiling" that was significantly higher than in comparable other plants of the same company, where the processes were partially carried out in-house.

These positive results from the implementation provide support for the adequacy of the chosen standard partnering approach. At the same time, they created the expectation that also financial results would develop similarly and provide improvements.

Surprisingly, the financial improvements over this 24 four-month period turned out to be insignificant. Even partnerships with explicitly supporting incentive agreements (Cases 9 and 10) did not generate any financial improvements over time. Various attempts (e.g. continuous improvement programs) in the form of inter-organizational approaches to achieve such improvements to the benefit of the involved parties failed.

Finally, the disillusioning résumé had to be drawn that the financial goals of partnering were not achieved based on the standard approach. In order to rule out alternative reasons for this, rival explanations, which could explain the outcome, had to be checked (Yin, 2009, p. 135). We checked the most obvious potential rival explanations. First, errors during implementation and second the possibility that the system may have already reached such maturity in the early phases that no further opportunities for financial performance improvement remained. The first possibility could be ruled out after a thorough check of the implementation project (e.g. feasibility, project preparation, execution and reporting). For the second possibility, comparable in-house business areas in three similar plants of the same company were analyzed and in all cases significant financial improvements had been achieved by their own functional units. Therefore, it was concluded that the applied standard approach did not provide an adequate basis for long-term partnership-improvements in terms of financial results.

Consequently, a somehow broader review of the partnership performance framework was needed to overcome the shortcomings of the standard partnering approach. For this a follow-up project was established with the aim to better understand the financial performance related issues of the partnerships and its obstacles and consequently bond the partners into a continuous performance improvement process, which provides mutual benefits. This was done in the form of the focal group project with a selected sub-group from the 13 cases.

\subsection{Stage 3 (focal group project for financial performance improvement)}

For the focal group partner performance project, again, a team structure was established with a similar cross-functional approach and procedures as in the first stages. This stage was initially planned for a 12 months period and eventually extended to 24 months.

\section{Partner management}

241 


\section{IJPDLM} 43,3

242
An insight of project stages 1 and 2 was that all three identified partner sub-types (Table I) had shown similar patterns in the development of performance. Thus, only one group was elected for the third stage. The logistics service providers qualified best due to their above mentioned characteristics (Section 3.2) and the high financial value of outsourced services.

New enablers were defined using the following logic. Again, the broad perspective of the EFQM model reaching from strategy to processes was adopted, this time with special focus regarding the achievement of financial results. The new enablers were decided upon after consulting all relevant stakeholders of the focal company (e.g. purchasing, operations and partner management) and presented to a partner and project steering committee. Finally, to get a maximum of insights about links and interdependencies between financial performance and the possible enabling systems elements and, hence, the effectiveness of each approach, slightly different "quasi-experimental" settings were created (Yin, 2009, pp. 9, 12). The following figure gives an overview of the complete set of new applied enablers similarly adapted in several management contexts (Eriksson et al., 2009) (Figure 5).

The third significant point of this approach is the adoption of the EFQM-inherent enabler logic that highlights the requirement that enablers must be managerially accessible. This helps surpass a frequently mentioned problem in literature that certain partnership-characteristics in the short run cannot be developed (e.g. corporate culture, trust, commitment) (Lambert et al., 1996) by identifying enablers, which are managerially accessible. They are complementary to the later discussed more structural elements of the partner system (e.g. asset structure, production link), which cannot be modified in the short-term. Structural elements together with the accessible enablers make up the complete partner system (Appendices 2 and 3). The new enablers entail a total of ten elements, as depicted in Appendix 3. For the purpose of this research we structure the elements in three categories briefly presented as follows.

First, the vision and strategy category. Its overall intention is to allow managers to evaluate technical, organizational, and cultural partner skills and to foster the partner's understanding and commitment to a partnership. In order to do so three enablers elements were designed, partner assessment, top-management involvement and vision building.
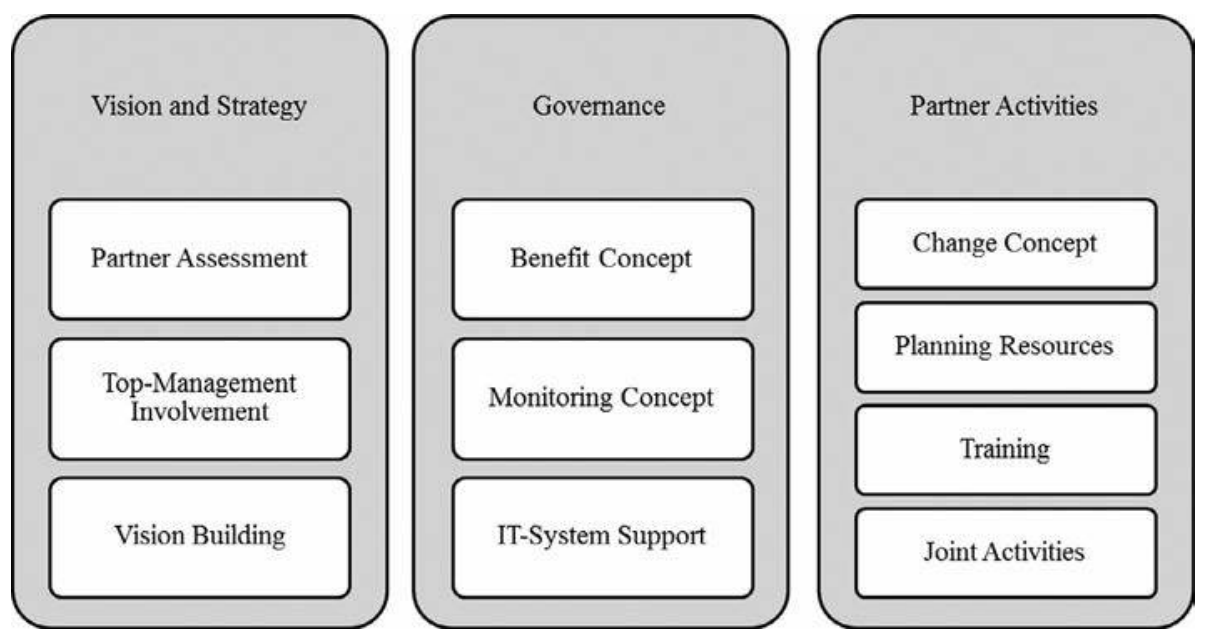

Figure 5.

Enabler categories with set of new "active" enabler elements 
Aligning a company's vision is renowned to be a central issue and has been widely adapted in literature for partnership-development by assessing drivers and facilitators of forming a long-term joint vision. Consequently, a partner assessment that assesses the "readiness" is within this category. For this purpose, interactive assessment meetings with relevant partners were held where ratings on a 1-3 scale for the operational and strategical "readiness" were given by the partner management team. The top-management involvement was intended to bond the top management of both partner sides into the project. Besides, there is a vision building element. Its aim is to provide a strong common understanding of the motivations and challenges, define (ambitious) goals, inspire a sense of mutuality and finally create commitment.

Second, the governance category comprises elements for rule setting, agreement of processes and systems. Their overall aim is to provide norms for processes and joint activities clustered in the partner activities category. Some supporting governance elements had been put in place right in the beginning of the implementation (Appendix 2, stage 2) (e.g. communication, error management) and insofar were present for all partners. In the focal group project, additional elements were implemented. Mainly because existing incentive rules in some contracts had proved to be ineffective, the benefit element was newly designed. It covers the new incentive rules to stimulate financial benefits, namely a cost-benefit sharing concept. This was deemed capable of providing financial improvements due to its innovative approach of compensation and reallocation of costs and benefits (Riha and Radermacher, 2009). Besides, this concept, other approaches were tested. The remaining monitoring and IT support elements provide tracking support for the financial results and related activities such as planning, joint operation control, communications or administrative purposes.

Lastly, the partner activities category has operational focus and comprises joint activities starting with the change concept. This is a rather complex element designed predominantly to elaborate a master plan for organizational change in the partner relationship, focusing on performance improvements and therefore is a key enabler. Planning resources is focusing upon new planning resources for process analysis and process reengineering, which had shown to be critical with some of the partners, training, consequently, is aiming at aligning methods and techniques on the operational level. Joint activities is the element where joint projects on the shop floor level were addressed. In sum, the partner activities category covers elements, aiming to provide effective approaches for actions to reach financial improvements. Recent empirical research confirmed a high overlap between these enablers and elements found to be significant for successful performing partnerships (Fawcett et al., 2008; Richey et al., 2010). This nurtured the expectation of significant results of the focal group project.

For three of the four partners different combinations of the abovementioned enabler elements were implemented, whereas one partner was treated as control and only received general information about the new financial improvement approach and expected financial benefits. All approaches are similar regarding the high relevance, which was given to vision building and the implementation of distinct benefit concepts, differing gradually in their focus. This was due to the high importance all involved stakeholders and also literature attribute to these enablers. For the other enablers the application and/or degree of intensity was varied to get broad feed-backs about the impact of each enabler. For an overview Table III.

\section{Partner management}

243 


\section{IJPDLM}

43,3

Table III.

Differing approaches between partners

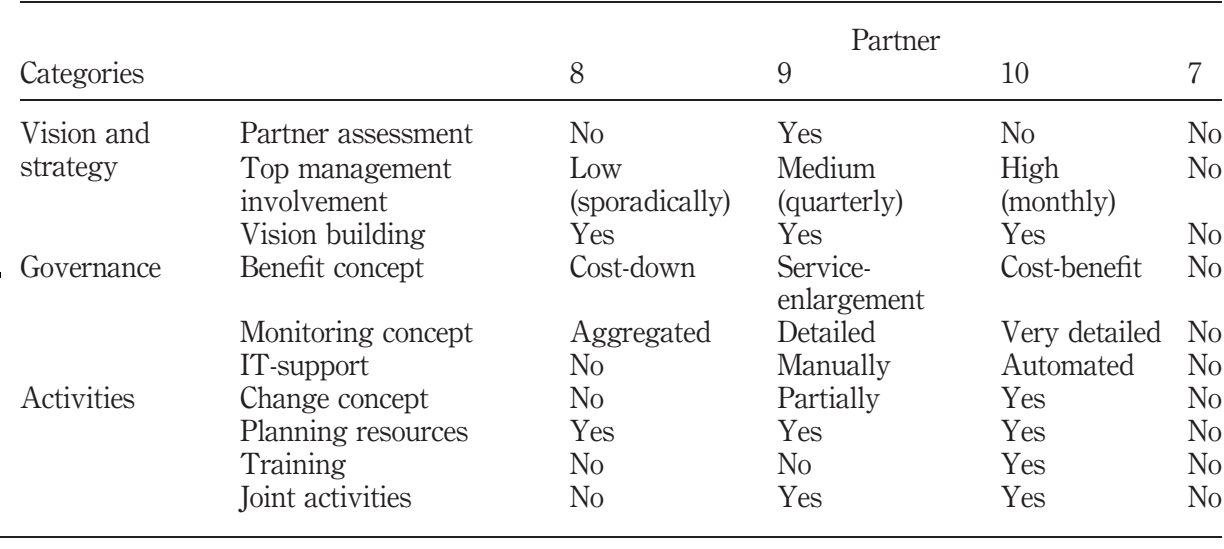

In the focal group project, substantial financial results were achieved in different forms.

For partner 8, financial improvements were achieved and passed forward based on jointly agreed process adjustments, i.e. of the type adjusted service levels at lower cost.

For partner 9, improvements and corresponding financial results of the type higher service levels at the same cost were reported by the partner and passed forward to the OEM.

For partner 10, costs and benefits were jointly evaluated and distributed between the partners. These improvements were of the type same service level at lower cost.

For the reference partner (where "nothing" was done) service cost reductions alleging process improvements were offered, i.e. of the type same service level at lower cost. But, strong doubts regarding the reported improvements remained. These doubts confirmed in a twofold way. Due to labor regulations frequent audits have to be made to guarantee that partner processes are still in conformity with the legal requirements. This was an excellent way to check whether processes had changed (i.e. economically improved). A second one was a joint evaluation of a core process were frequently problems had occurred. In neither case changes nor to the worse nor to the better could be confirmed. So, there really was no plausible proof of process improvements, which could have justified the cost reductions. It had to be concluded therefore that the reported improvements characterized mere redistributions of money from the service partner to the customer because of implied pressure to show results, a phenomenon known as Hawthorne effect (Tompkins, 2005, p. 156).

From the financial effects observed, different conclusions can be drawn: first, the active interventions that were added in stage 3 of this research were effective[1] in terms of improved financial results; second, "mere talking" as done in the case of the reference partner is figuratively like doing nothing and only shows financial results in terms of different cost allocation.

The fact that different approaches yielded positive results reveals that more than one unique success pattern may exist. This refers to the question about the interdependencies between the enablers and which of them are more relevant for the financial outcome than others. For this purpose the systems thinking approach of Vester (2007) was used. The aim of this method is to understand the behavior of complex 
systems and avoid narrow thinking by concentrating on a few enablers only. The complete framework is visualized in the following table. For a detailed description, see Appendices 2 and 3 (Table IV).

In a next step the systems elements were analyzed with the help of this method to identify the character of each of the elements. First, for all 18 elements the ingoing and outgoing impact was estimated and compiled in the impact matrix (Figure 6) where the strength of influences between all system elements have a value between 0 and 3.

Based on this, in the next step the role allocation matrix is derived positioning all elements with regard to their systemic interconnectedness (Figure 7). The matrix places system elements with rising criticality from the lower left to the upper right area whereas active elements are placed on the upper left turning to those with reactive character at the lower right.

For the purposes of system changes, active elements are ideal as they interact with other system elements in such a way that they strongly influence other elements and conversely only receive weak stimulus from other elements. Thus, they are also able to stabilize a system. For critical elements only successive interventions are recommended, because of strong interdependencies, so that strong feedbacks may accelerate the system in an unwanted and uncontrolled manner. Intervening at reactive/buffering elements is not useful, because interventions only produce "cosmetic" changes. Reactive elements make good indicators for system changes as they react most markedly to changes in the system, i.e. they receive strong impacts, which signals that system change is happening. Neutral elements are difficult for the purposes of system steering. They influence other elements to the same degree as they receive impacts from other elements; hence, they behave like system stabilizers.

\begin{tabular}{ll}
\hline Phase/category & Partnership element \\
\hline Contract phase (stage 1) & Contract I (completeness) \\
& Contract II (limitation) \\
& Role model \\
& Asset specificity \\
Integration phase (stage 2) & Agency type \\
& Production link \\
& Training on the job concept \\
& Communication concept \\
Vision and strategy (stage 3) & Error/change management \\
& Audit \\
Governance (stage 3) & AÜG project \\
& Partner assessment \\
& Top management involvement \\
Activities (stage 3) & Vision building \\
& Benefit concept \\
& Monitoring concept \\
& IT-support \\
& Change concept \\
& Planning resources \\
& Training for improvement \\
& Joint activities \\
& \\
&
\end{tabular}




\section{IJPDLM \\ 43,3}

\section{6}

Figure 6.

Impact matrix of partnership-framework
Figure 7.

Systemic role allocation of enabler elements

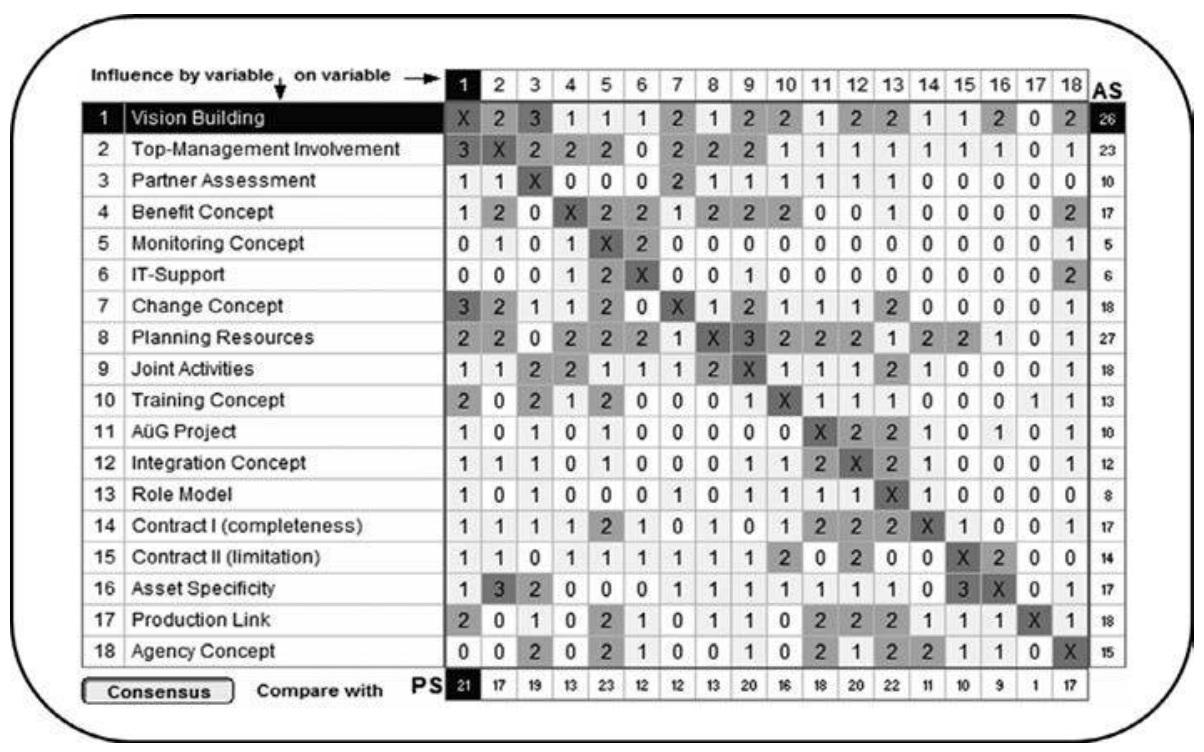

Source: Screenshot: Prof. Vester Sensitivity Model ${ }^{\circledR}$

This matrix gives a comprehensive impression of the role of the elements and of the character of the system as a whole. The discussion of the role allocation is the most significant step to an understanding of the inherent effects of the system. Within the matrix, three significant clusters of enablers could be identified: control levers, accelerators and indicators. Not all of them are in the same way accessible. "Structural" elements, e.g. production link, asset specificity and to a lesser degree contract issues are more difficult to modify in the short-term or by each partner alone than other system 
elements within an operating system. Thus, for purposes of interventions they are less managerially accessible (see elements in brackets in Figure 7).

Starting with the accelerators that are able to get "things" in motion, these are the four elements: vision building, planning resources, top-management involvement, and joint activities. Due to their systemic interconnectedness, it is important to notice that these critical elements (high active and passive sum) also offer a reactive potential and therefore may be affected by repercussions of their own use. Thus, these elements ideally should be bound in feedback loops that finally stabilize the system.

Second, there is the cluster with potential control levers, which serve for interventions, which jointly also stabilize the system. Besides, the change concept, the benefit concept, and the training concept, the structural elements of contract, asset specificity, and production link are located in this area. Due to their position, they have relevant impacts on several other elements (considerable high active sum) and only receive moderate inputs from other elements (low passive sum), hence are ideal for corrections and probably have to be used several times.

Lastly, there are the indicators, which, besides the governance-related elements from the standard approach, comprise partner assessment and monitoring concept. Due to their systemic role (low active sum but high passive sum) they chiefly receive impacts from other elements and thus signal system changes, which sometimes may be a misleading signal for interventions in this area for further improvement activities. Due to their systemic interconnectedness, such interventions tend to be compensated by self-regulation and can shroud the clear perspective on the nature of the system, and even may cause undesired collateral effects.

Some interesting observations occurred. Several of the "structural" elements (e.g. asset specificity and production link) achieved prominent allocations in the impact matrix as active elements, which can spur the development of a performance oriented partnership. The production link emerged as strong control lever that interestingly cannot be triggered from within the system as it is because its passive sum is only 1 , the lowest in the system. However, it has a strong influence on many other variables. To a lesser degree this also holds true for asset specificity. A surprise was revealed with the benefit concept. It only emerged as a smooth lever within the control lever cluster. This on the one hand is in fit with prior experiences in the initial project phase where two partnerships with mutual contractual benefit concepts did not yield results. Therefore, the characteristics of the benefit concept identified in the systemic analysis confirm that standing alone, this element probably does not have a sufficient impact to get a system in motion or its impact may only have a short-term effect (Appendix 5). On the other hand this is somehow counter-intuitive to the basic economic principle and corresponding theory that people strongly respond to incentives, i.e. benefits (Bolton and Dewatripont, 2005, p. 14). This is discussed in more detail in Section 5.

System thinking also offered a new view on some other frustrating experiences with incentive mechanisms that had even produced counterproductive performance effects, which are briefly illustrated in two examples (A and B) in the following. In example A, an incentive agreement that penalizes order-picking errors from the first error on had been agreed upon with partner 10. Despite the seemingly accepted rationale behind this mechanism, the workers felt a penalizing mechanism that started from the first error on was highly unfair. Instead of focusing creative energy on how to achieve the target, it became more "popular" to argue against such type of mechanism. The acceptance of this 


\section{IJPDLM 43,3}

\section{8}

mechanism eroded what finally led to a decline in quality to levels even below the starting level. In example $\mathrm{B}$, a partner had insured the financial risk of a penalty. This had a (desired) reverse effect on the risk and a wrong effect on the effectiveness of the penalty incentive when this fact reached the work floor workers. The workers, quickly looking through the mechanism, understood that any penalty would not have any negative financial effect. The agreement became ineffective (Figure 8).

How are these observations to be interpreted? In order to clarify this and to deepen the understanding, post hoc interviews with service providers were carried out after finishing research stage 3. The aim was to access their knowhow from a broad range of outsourcing projects with many customers and provide a better understanding regarding the above observations. Thus, three further in-depth interviews with executives of service providers were conducted, one representing the focal group, the others the two other sub-types of service providers. The executives' views of business partnership were gathered in a split structure: a questionnaire quantifying the importance and presence of certain relationship characteristics that was adapted from recent empirical research (Richey et al., 2010) and a structured interview. The results are discussed together with the findings of the systemic analysis in the next section.

\section{Discussions and implications}

First, the application of a standard partnering approach has shortcomings regarding the financial performance of business relationships analyzed in this research. This shortcoming could partially be overcome by intervening in distinct areas of several partnerships (focal group). Second, the results of the AR presented in this paper make clear that causes and interdependencies between distinctive elements in a partnershipframework are critical for the design of a successful partner-performance management. Applying a systemic thinking approach, the systemic character and role of the elements becomes much clearer. For the purposes of a successful performance orientation, some elements can be used more effectively than others can. This insight is confirmed by the

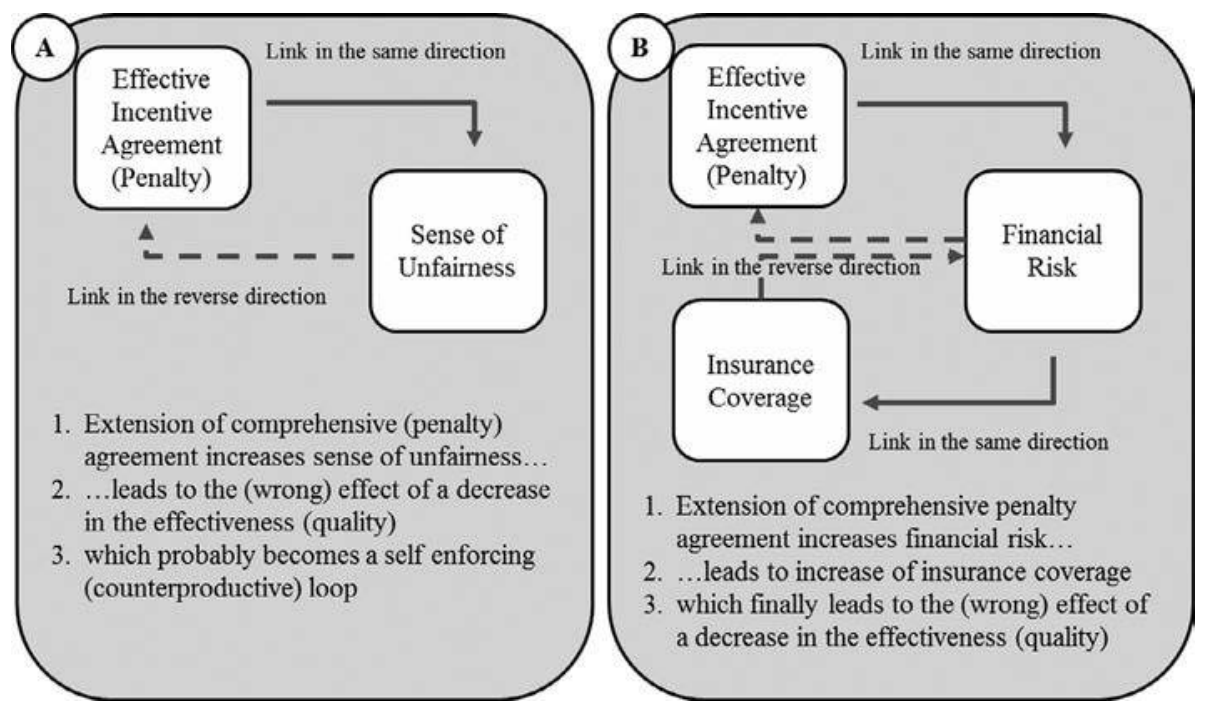

Figure 8.

Examples of counterproductive feedback loops 
post hoc interviews, explicitly for the enablers vision and joint activities, which are seen to be highly efficient to foster performance. The interviews also confirmed the importance of the governance related elements for the successful development of performing partnerships. Interestingly, different from the former two the gap between importance and presence was the lowest for this category. This casts an interesting light on the interpretation of the role of governance elements in general. The low gap indicates that the governing rules of partnerships in general are perceived to be satisfying and thus the interviewees do not expect any further (performance) improvement induced by "more governance". Insofar, the cross-functional design of the partner management in the standard approach, which was highly rated by the partners, deems to be adequate to implement a good governance framework that is important for the development of partnerships. However, it also implicates that the standard approach that mainly relied on the implementation of governance concepts in the early stage of the research did not yield the aimed performance improvements because these elements alone are not sufficient and are not the most effective drivers of partnership performance. Summarizing, post hoc interviews confirm that governance in a systemic interpretation is "only" an indicator and not an accelerator for performance. The insight that the adherence to norms is necessary but not sufficient for a performing partnership has also been confirmed in recent empirical research (Palmatier et al., 2007). On the contrary, the financial success of the enhanced approach, hinted by the role allocation model and interviews, built much more on interventions which aim to create vision, hence commitment, and joint activities, hence create relationship specific investment (RSI). The latter effect, also confirmed by the role allocation model may be even leveraged by structural elements, for example a close production link and high asset specificity (Dyer, 1997). This insight is confirmed by the research of Palmatier et al. (2007) who similarly found that commitment and RSI are key drivers for performance in seller-distributor relationships. Our results would indicate that this finding also holds for manufacturer-service provider partnerships.

Contrastingly, permanent interventions in the partnership development process may be a double-sided coin. Feedback from partner employees revealed that frequent interventions from the focal company and a close production link may turn out to be undermining the partners independence and hence its entrepreneurial spirit down to the workforce. This is a facet of dependence which points to a similarly undesired feedback like in the above-mentioned example for wrong incentives (p. 23). To the best of our knowledge, this is rarely discussed in literature but deserves special attention when designing the role model of partnership.

Most surprising are the various facets of the benefit concept. Counter-intuitively to economic principles the systemic analysis revealed that they do not exert strong influence on the performance of partnerships. In contrast to this finding interviewees think that benefit concepts have a very high importance and, even worse, saw a high gap between importance and presence of this enabler. Still more confusing, "incentive" mechanisms in practice are deemed to be highly unfair regarding the distribution of benefits and risks. Interviewee no. 1: "sharing rules suggested by the focal companies often are an affront to the sense of fairness". They claim that mechanisms usually miss reward opportunities. Interviewee no. 2: "budget driven thinking is a serious obstacle to the implementation of reward systems". Customers have a problem with "over-performing service providers" or, even worse, they are seen as hidden tools for additional cost reductions for the customer side as mentioned by interviewee no. 1 . Thus, benefit concepts sometimes suffer from 
IJPDLM

43,3

250 counterproductive attitudes or arrangements and become ineffective. This confirms the long existing reality: the mere existence of an agreement does not guarantee the alignment of partners and therefore the desired results. It even can be counterproductive as was shown above in the two examples. The "wrong" feedback loops in the examples partially illustrate this fact because strong incentive agreements might even lead to pre-calculation of future expected benefits, which is counterproductive for a competitive partnership. Partners even may be risk-averse and would prefer to live without any incentive agreement at all and rather rely on fixed payments. The agreement itself might not be much more than a lip confession under the pressure of the customers' wishes and expectations as it was hinted in some expert interviews. As a consequence, of this multi-faceted characteristics, the systemic analysis has probably rightly relativized the role and potential influence of benefit concepts on partnership performance. The above insights also support the understanding that partner management in practice is not where it expected itself to be. While the promised benefits of partnerships are far from being fully exploited major obstacles for the successful implementation of financial performance oriented partnerships still exist.

\section{Conclusions}

\subsection{Practical and theoretical contribution}

The findings of this paper shed light on partner management issues that have been considered in literature and practice, but are not yet fully understood and require more empirical investigation (Palmatier et al., 2007). The focal issue of this longitudinal research is the beneficial link between collaboration and partnership performance. This study shows that an interconnected systemic thinking approach reveals insights about how to achieve these benefits which cannot be deduced from analyzing individual relationships on a cause-effect basis between two or a few elements on their own. From a theoretical perspective, without systemic thinking a similar profound understanding of the interconnectedness of the elements of a partnership would not have been achieved. Conversely, this implies another theoretical contribution. Partnerships are complex, which means that their elements cannot be "isolated" and adequately analyzed with the aim to understand and influence the behavior of the system as a whole. This is in line with recent research approaches, which emphasize the fruitful insights derived from an application of various theoretical approaches (i.e. a broader and therefore more comprehensive perspective) to understand today's business phenomena (Frankel et al., 2008). The conclusion that partnerships are complex is also confirmed by recent empirical research (Fawcett et al., 2008; Richey et al., 2010), which showed that it is critical for managers to identify the enabling elements that spur the performance of partnerships. Additionally this research provides the example of a concrete role model of system elements for a manufacturer-service provider partnership, which managers could use to better identify levers, which influence the partnership development in their current cases. Finally, this research presents a powerful and simple systemic thinking model which managers could apply when aiming to improve the performance of their business partnerships (see guideline in Appendix 6).

Corresponding to the above-mentioned limitations of simplistic cause-effect thinking, functional organizations show limitations which create a gap in their ability to fully exploit the potential of partnerships. This is due to their functional focus on distinct aspects of the development of business relationships (i.e. purchasing: "stationary" 
contract design; operations/production: process implementation). Insofar, partner management designed as a cross-functional unit is a concept, which can fill this gap by actively implementing an enabler framework that spans functional boundaries and the firms. This approach on the one hand fits the need for a "supplemental integrating device" (Lawrence and Lorsch, 1969, p. 13) and on the other hand signals the customers' concern with the success of the partnership (Dyer and Chu, 2000). This provides the basis for a mutually beneficial development of partnerships.

In this regard, stimulating an appropriate level of activities beyond mere rule setting has been found to be a critical issue. Strong interventions aiming to stimulate such activities took place in stage 3 of this study, namely in form of vision-building, joint planning and joint activities. In this context, post-study interviews provided another important insight: governing business relationships with the exception of incentives seems to be in good shape, but good governance rules, however sophisticated they may be, alone are not good enough to stimulate financial improvements. This extremely relevant practical conclusion would be strengthened even more if the major gap revealed in post-study interviews between the high importance of joint activities concepts and their rare usage were generalizable. Recent empirical studies (Novak and Stern, 2008), which confirm a performance gap for outsourced activities in comparison to in-house functions, hint in this direction. Similar importance has been attached to common visions as key for effective management (Collins and Porras, 1996; Etzioni, 1971, p. 422). The findings of Dyer and Chu $(2000,2011)$ for supplier-automaker relationships highlighting the role of "process based" activities also support our conclusion pointing at both, rules for governance and concrete activities, as antecedents for performing partnerships.

For this purpose, this research provides a framework and a generic step-by-step guideline for implementing mutually successful partnerships. It combines the EFQM model for excellence and an interlinked thinking method. This broadens "conventional" governance based management approaches by establishing two additional categories, which are critical for the establishment of a performance oriented business relationship. Elements within the Vision category and the partner activities category proved to be critical control levers and accelerators for performance. It is valuable for practitioners in their day-to-day business to possess the knowledge about causal relatedness of drivers, which allows for a cautious assessment of the potential of the elements of a partnership performance framework.

\subsection{Avenues for future research}

Based on the insights into the governance elements in a partnership, one brief conclusion from the above section could be: "activities matter!" However, there was one already mentioned exception within the governance category: the benefit concept appeared to be one of the most critical elements regarding the gap between relevance and usage. According to principal agent literature benefits are part of incentives, which are widely based on mechanisms like pricing schemes, control and ownership rights (Bolton and Dewatripont, 2005). There are relevant calls for research regarding the effectiveness of incentive schemes, specifically pricing schemes (Lukassen and Wallenburg, 2010). This fits the findings of this study, which revealed major discrepancies in this field, explicitly in the perception of incentive schemes by service providers. Fairness was revealed to be a "hidden" issue in the effective design of incentive systems. The detected thinking patterns and responses of employees to certain incentives made clear that the question of how norms and attitudes 
IJPDLM

43,3

252

interact with incentives deserves more attention to be able to adequately design high performing business relationships (Laffont and Martimort, 2002, p. 3). Recent empirical research has also confirmed this issue (Fehr et al.,2007). Thus, it remains an important issue for future research to better understand how incentive schemes can be designed, which stimulate the full effort of the service partners.

This study was based mainly on longitudinal experience with partners from the logistics service provider field and insofar limited regarding the question whether the insights are generalizable for other service providers or suppliers. Some similar empirical findings for seller-distributor relationships appear promising in this direction. Nevertheless, relevant differences between LSP and other supplier relationships remain, probably most prominently the fact that services due to their intangible nature on the one hand provide more difficulties to be "asset specific", on the other hand services tend to be highly integrated in customer processes. Following the findings of recent research (Palmatier et al.,2007) asset specificity and integration strongly influence the performance of a partnership. For LSP's, their characteristics may cause opposite performance impacts. Which one prevails cannot be answered at this point.

Finally, our study covered the evolution of partnering relationships over a four-year period, including the focal group project. It remains to be explored whether partnerships would generate the financial benefits applying the insights of the focal group project but without such dedicated attention.

\section{Note}

1. Replication of outcome in three cases is a strong indicator for the robustness of the conclusion (Yin, 2009, p. 54).

\section{References}

Akerlof, G.A. and Shiller, R.J. (2009), Animal Spirits, Princeton University Press, Princeton, NJ. Ariño, A. (2003), "Measures of strategic alliance performance", Journal of International Business Studies, Vol. 34 No. 1, p. 66.

Autry, C.W. and Golicic, S.L. (2010), "Evaluating buyer-supplier relationship-performance spirals: a longitudinal study”, Journal of Operations Management, Vol. 28 No. 2, pp. 87-100.

Barratt, M., Choi, T.Y. and Li, M. (2011), "Qualitative case studies in operations management: trends, research outcomes, and further research implications", Iournal of Operations Management, Vol. 29, pp. 329-342.

Binder, M. and Clegg, B. (2007), "Designing and managing collaborative enterprises in the automotive industry", International Iournal of Logistics: Research and Applications, Vol. 10 No. 2, pp. 135-152.

Bolton, P. and Dewatripont, M. (2005), Contract Theory, MIT Press, Cambridge, MA.

Brennan, R. (1997), "Buyer/supplier partnering in British industry: the automotive and telecommunications sectors", Lournal of Marketing Management, Vol. 13, pp. 759-774.

Busse, C. (2010), "A procedure for secondary data analysis: innovation by logistics service providers", Lournal of Subplv Chain Management, Vol. 46 No. 4, pp. 44-58.

Collins, J.C. and Porras, J.I. (1996), "Building your company's vision”, Harvard Business Review, Vol. 74 No. 5, pp. 65-77. 
Deepen, J.M., Goldsby, T.J., Knemeyer, A.M. and Wallenburg, C.M. (2008), "Beyond expectations: an analysis of logistics outsourcing goal achievement and goal exceedance", Lournal of Business Logistics, Vol. 29 No. 2, pp. 75-105.

\section{Partner management}

Dubé, L. and Paré, L. (2003), "Rigor in information system positivist case research: current practices, trends, and recommendations", MIS Quarterlv, Vol. 27 No. 4, pp. 597-634.

Duffy, R. and Fearne, A. (2004), "The impact of supply chain partnerships on supplier performance", International Iournal of Logistics Management, Vol. 15 No. 1, pp. 57-71.

Dyer, J.H. (1997), "Effective interfirm collaboration: how firms minimize transaction costs and maximize transaction value", Strategic Management Iournal, Vol. 18 No. 7, pp. 535-556.

Dyer, J.H. and Chu, W. (2000), "The determinants of trust in supplier-automaker relationships in the US, Japan, and Korea”, Iournal of International Business Studies, Vol. 31 No. 2, pp. 259-285.

Dyer, J.H. and Chu, W. (2011), "The determinants of trust in supplier-automaker relations in the US, Japan, and Korea: a retrospective”, Journal of International Business Studies, Vol. 42 No. 1, pp. 28-34.

EFQM (2011), Introducing the EFQMExcellence Model, available at: www.efqm.org/en/PdfResources/ Introducing \%20the \% 20EFQM\%20Model\%20\%28public\%29.pdf (accessed 20 March 2011).

Eggert, A., Ulaga, W. and Schulz, F. (2006), "Value creation in the relationship life cycle: a quasi-longitudinal analysis”, Industrial Marketing Management, Vol. 35 No. 1, pp. 20-27.

Eisenhardt, K.M. (1989), "Building theories from case study research”, Academv of Management Review, Vol. 14 No. 4, pp. 532-560.

Ellram, L.M. (1991), "Life-cycle patterns in industrial buyer-seller partnerships", International Lournal of Phvsical Distribution \& Logistics Management, Vol. 21 No. 9, pp. 12-20.

Eriksson, P.E., Atkin, B. and Nilsson, T. (2009), "Overcoming barries to partnering through cooperative procurement procedures", Engineering. Construction and Architectural Management, Vol. 16 No. 6, pp. 598-611.

Etzioni, A. (1971), The Active Society, The Free Press, New York, NY.

Fawcett, S.E., Magnan, G.M. and McCarter, M.W. (2008), "A three-stage implementation model for supply chain collaboration”, Journal of Business Logistics, Vol. 29 No. 1, pp. 93-112.

Fehr, E., Klein, A. and Schmidt, K.M. (2007), "Fairness and contract design", Econometrica, Vol. 75 No. 1, pp. 121-154.

Frankel, R., Bolumole, Y.A., Eltantawy, R.A., Paulraj, A. and Gundlach, G.T. (2008), "The domain and scope of SCM's foundational disciplines - insights and issues to advance research", Journal of Business Logistics, Vol. 29 No. 1, pp. 1-30.

Gudehus, T. and Kotzab, H. (2009), Comprehensive Logistics, Springer, Dordrecht.

Gulati, R. (1998), “Alliances and networks”, Strategic Management Journal, Vol. 19 No. 4, pp. 293-317.

Hofer, A.R., Knemeyer, A.M. and Dresner, M.E. (2009), "Antecedents and dimensions of customer partnering behavior in logistics outsourcing relationships", Lournal of Business Logistics, Vol. 30 No. 2, pp. 141-159.

Knemeyer, A.M., Corsi, T.M. and Murphy, P.R. (2003), "Logistics outsourcing relationships: customer perspectives”, Journal of Business Logistics, Vol. 24 No. 1, pp. 77-109.

Laffont, J.-J. and Martimort, D. (2002), The Theory of Incentives: The Principal-Agent Model, Princeton University Press, Princeton, NJ. 
IJPDLM

43,3

254
Lambert, D.M., Emmelhainz, M.A. and Gardner, J.T. (1996), "Developing and implementing supply chain partnerships", The International Journal of Logistics Management, Vol. 7 No. 2, pp. 1-17.

Lambert, D.M., Emmelhainz, M.A. and Gardner, J.T. (1999), "Building succesful logistics partnerships", Journal of Business Logistics, Vol. 20 No. 1, pp. 165-181.

Lambert, D.M., Knemeyer, A.M. and Gardner, J.T. (2004), "Supply chain partnerships: model validation and implementation”, Journal of Business Logistics, Vol. 25 No. 2, pp. 21-42.

Langley, C.J. Jr (2010), 2010-Third Party Logistics: 15th Annual Study, Capgemini Consulting, Paris.

Lawrence, P.R. and Lorsch, J.W. (1969), Developing Organisations: Diagnosis and Action, Addison-Wesley, Reading, MA.

Lemke, F., Goffin, K. and Szwejczewski, M. (2003), "Investigating the meaning of supplier-manufacturer partnerships", International Iournal of Phvsical Distribution \& Logistics Management, Vol. 33 No. 1, pp. 12-34.

Lukassen, P.J.H. and Wallenburg, C.M. (2010), "Pricing third-party logistics services", Transportation Iournal, Vol. 49 No. 2, pp. 24-43.

Lunnan, R. and Haugland, S.A. (2008), "Predicting and measuring alliance performance: a mulitdimensional analysis", Strategic Management Journal, Vol. 29, pp. 545-556.

Mentzer, J.T., Min, S. and Bobbit, L.M. (2004), "Towards a unified theory of logistics", International Iournal of Phvsical Distribution \& Logistics Management, Vol. 34 No. 8, pp. 606-625.

Mentzer, J.T., Min, S. and Zacharia, Z.G. (2000), "The nature of interfirm partnering in suppy chain management”, Journal of Retailing, Vol. 76 No. 4, pp. 549-567.

Mohr, J. and Spekman, R. (1994), "Characteristics of partnership success: partnership attributes, communication behavior, and conflict resolution techniques", Strategic Management Journal, Vol. 15 No. 2, pp. 135-150.

Näslund, D., Kale, R. and Paulraj, A. (2010), "Action research in supply chain management - a framework for relevant and rigorous research”, Lournal of Business Logistics, Vol. 31 No. 2, pp. 331-355.

Novak, S. and Stern, S. (2008), "How does outsourcing affect performance dynamics? Evidence from the automobile industry", Management Science, Vol. 54 No. 12, pp. 1963-1979.

Palmatier, R.W., Dant, R.P. and Grewal, D. (2007), "A comparative longitudinal analysis of theoretical perspectives of interorganizational relationship performance", Iournal of Marketing, Vol. 71 No. 4, pp. 172-194.

Peters, T. (1991), "The boundaries of business: partners - the rhetoric and reality", Harvard Business Review, Vol. 69 No. 5, pp. 97-99.

Politis, Y. and Siskos, Y. (2010), "Self-assessment for measuring business excellence: the MUSABE method", Total Quality Management \& Business Excellence, Vol. 21 No. 11, pp. 1063-1083.

Richey, R.G. Jr, Roath, A.S., Whipple, J.M. and Fawcett, S.E. (2010), "Exploring a governance theory of supply chain management: barriers and facilitators to integration", Iournal of Business Logistics, Vol. 31 No. 1, pp. 237-256.

Riha, I. and Radermacher, B. (2009), "Cost benefit sharing-based coordination in logistics networks", International Journal of Information Technology and Management, Vol. 8 No. 2 , pp. 161-177.

Rodrigues, A.M., Stank, T.P. and Lynch, D.F. (2004), "Linking strategy, structure, process, and performance in integrated logistics”, Journal of Business Logistics, Vol. 25 No. 2, pp. 65-94. 
Senge, P., Kleiner, A., Roberts, C., Ross, R., Roth, G. and Smith, B. (1999), The Dance of Change, Random House, New York, NY.

Skarzauskiene, A. (2010), "Managing complexity: systems thinking as catalyst of the organization performance", Measuring Business Excellence, Vol. 14 No. 4, pp. 49-64.

Stank, T.P., Keller, S.B. and Daugherty, P.J. (2001), "Supply chain collaboration and logistical service performance", Lournal of Business Logistics, Vol. 22 No. 1, pp. 29-48.

Tate, K. (1996), "The elements of a successful logistics partnership", International Iournal of Phvsical Distribution \& Logistics Management, Vol. 26 No. 3, pp. 7-12.

Tompkins, J.R. (2005), Organization Theory and Public Management, Wadsworth Publishing, Belmont, CA.

Toni, A.D. and Tonchia, S. (2001), "Performance measurement systems", International Iournal of Operations \& Production Management, Vol. 21 Nos 1/2, pp. 46-70.

Ulaga, W. and Eggert, A. (2006), "Relationship value and relationship quality", European Iournal of Marketing, Vol. 40 Nos 3/4, pp. 311-327.

Vester, F. (2007), The Art of Interconnected Thinking: Tools and Concepts for a New Approach to Tackling Complexity, MCB Verlag, Munich.

Vitasek, K. and Ledyard, M. (2009), "Vested outsourcing: a better way to outsource", Supply Chain Management Review, Vol. 13 No. 6, pp. 20-27.

Vitasek, K., Ledyard, M. and Manrodt, K. (2010), "How to write a vested outsourcing contract", CSCMP’s Supply Chain Quarterly, Vol. 2, pp. 52-58.

Wallenburg, C.M. (2009), "Innovations in logistics outsourcing relationships: proactive improvements by logistics service providers as a driver of customer loyalty", Iournal of Supply Chain Management, Vol. 45 No. 2, pp. 75-93.

Wiendahl, H.-P., Dreher, C. and Engelbrecht, A. (2005), Erfolgreich Kooperieren, Physica-Verlag, Heidelberg.

Yin, R.K. (2009), Case Study Research, 4th ed., Sage, Los Angeles, CA.

Zacharia, Z.G., Nix, N.W. and Lusch, R.F. (2009), "An analysis of supply chain collaborations and their effect on performance outcomes", Lournal of Business Logistics, Vol. 30 No. 2, pp. 101-123.

Zimmermann, K. and Seuring, S. (2009), "Two case studies on developing, implementing and evaluating a balanced scorecard in dyadic distribution channels", International Iournal of Logistics: Research and Application, Vol. 12 No. 1, pp. 63-81.

(Appendices follow overleaf.) 


\section{IJPDLM}

\section{3,3}

\section{6}

Research question

Science and practice

Justification AR approach

Unit of analysis/context

Methods/triangulation

Role of researcher Access

Structure: categorization and pattern matching

Cyclical process/Project reviews

Presentation: logical chains, frameworks

Rigor and validity

\section{Case design}

Exploration: how do elements of partnership systems interact as a basis for an enhanced performance management framework Contribute to the practical immediate concerns of the studied organization and to the goals of science (explore link between partnership and performance improvement)

Participation of the studied organization in a cyclical process (partner implementation and performance improvement)

Single case (newly implemented automotive plant) with embedded units (13 in-plant business relationships with service providers of a total of 25 in-plant third parties which represent 1/3 of total work force on site). Focal project with four service providers. The industry is deemed to be a leader in SCM

\section{Data collection}

Data collection took place between 2005 and 2008. Multiple sources of evidence (formal (frequent/regular) contact within the established communication structure with managers and employees of partners, informal contacts with managers and employees of the partners, documents such as meeting minutes, contracts, presentation, internal documents and observations) and multiple researchers (partner management team with four members, which was headed by the author) were used. Clear role model of partner management team fosters minimum researcher bias

Head of partner management team

Access to information such as contracts, operational and financial data from ERP-system, which under normal circumstances is not accessible Data analysis

Time series analysis of time and quality data based on daily ERP data, analysis of cyclical partner opinion surveys for pattern matching. Items and scales used in opinion polls were developed in collaboration with central departments (purchase, legal affairs, strategy). Application of logic model concept following (Yin, 2009) Three-stage research concept, in stage 2 applying a stepwise phase concept for partner integration with cyclical reviews and learning loops applying the DEMING circle logic, in stage 3 establishment of focal project for purposes of performance improvement

Application of system interaction analysis (Prof. Vester Sensitivity Model ${ }^{\circledR}$ ), presentation of a role model for the system elements and enhanced framework for partner performance management For internal validity, the system interaction analysis provides an approach that overcomes the limitations of cause-effect thinking. The method was applied under observation of a trained user, closely following the necessary and recommended steps of the method (i.e. multiple coders, including the LSP side with experience with the case, use of formal coding sheet, sound application of the assessment logic) which assures the quality of the results. To assure the quality of the findings additional interviews were carried out with representatives of service providers, where the findings were reflected
Table AI.

Summary of the action research process 


\section{Appendix 2}

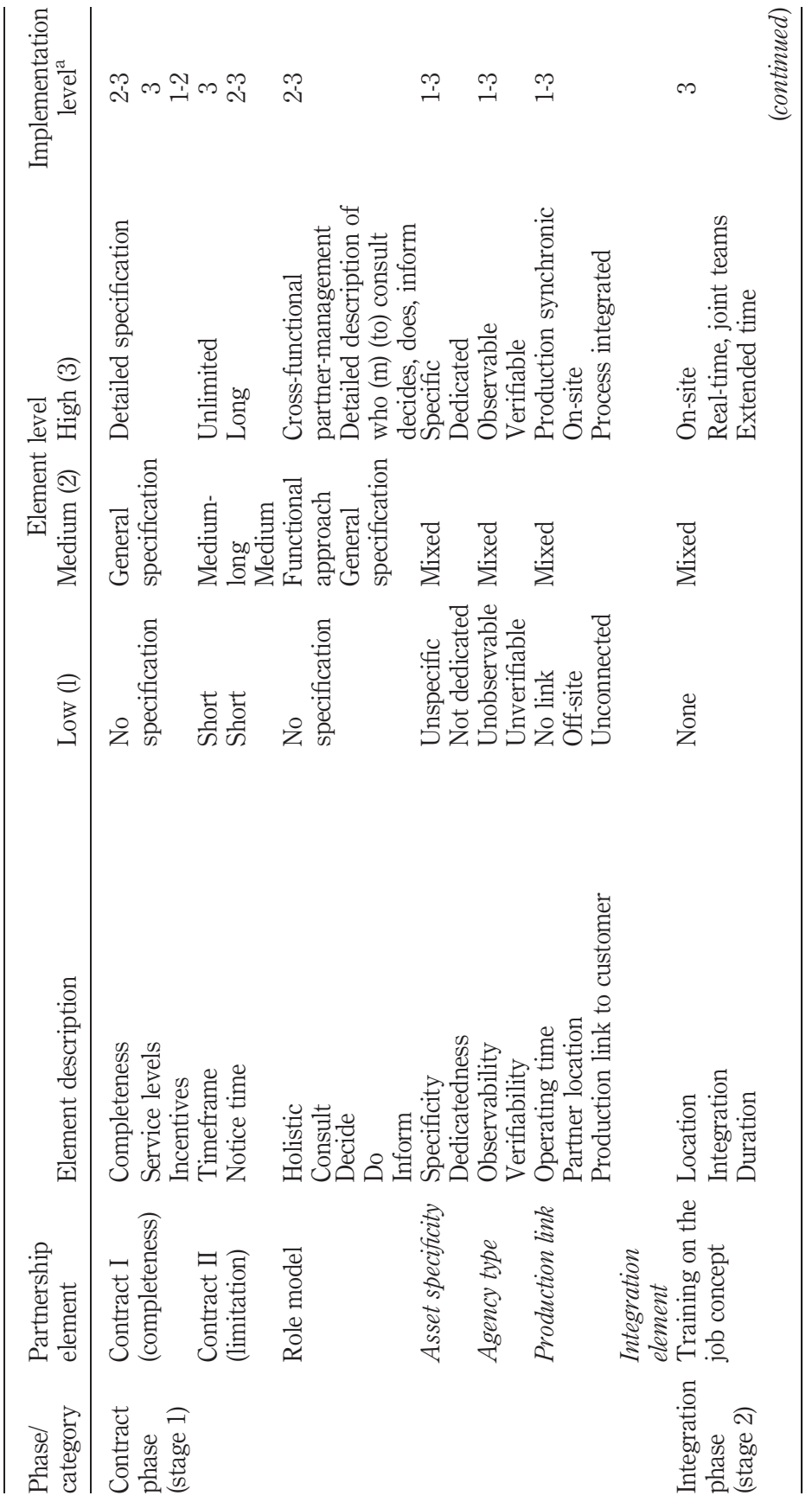

Partner management

257 


\section{IJPDLM \\ 43,3}

258

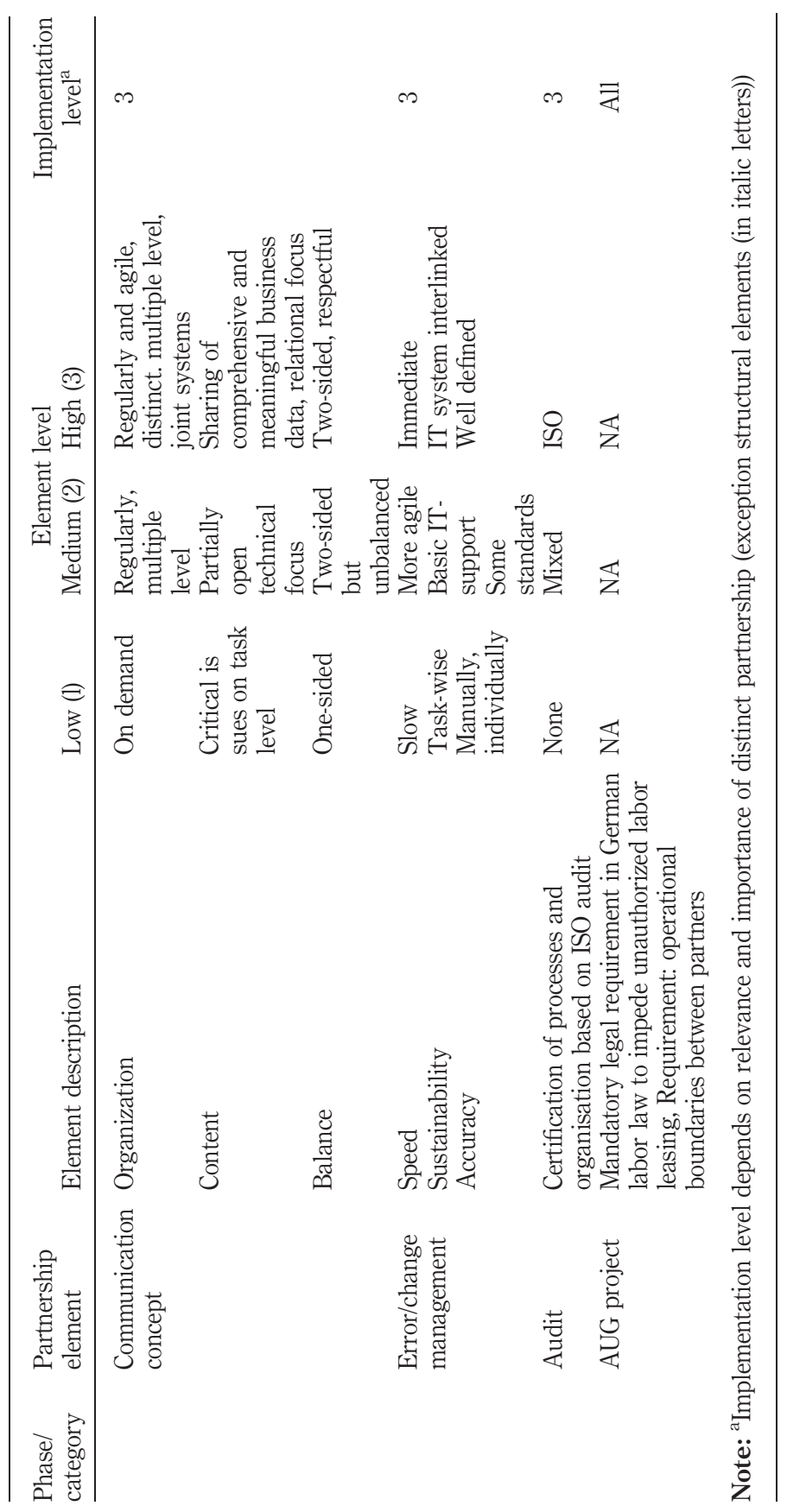


Appendix 3

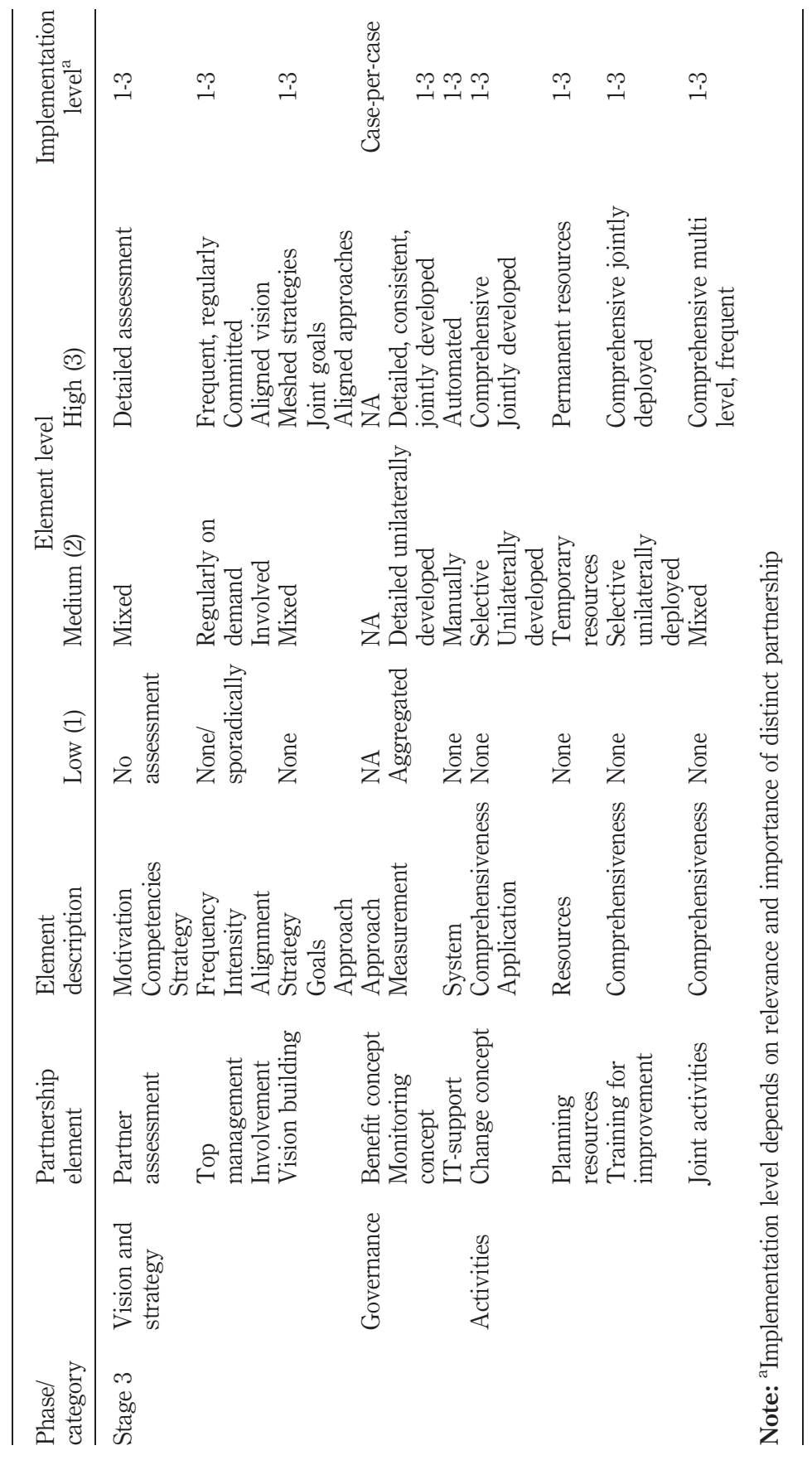

Partner management

259
Table AIII.

Enhanced approach description (stage 3) 


\section{IJPDLM}

43,3

\section{0}

Figure AI.

Systemic role interpretation

\section{Appendix 4}

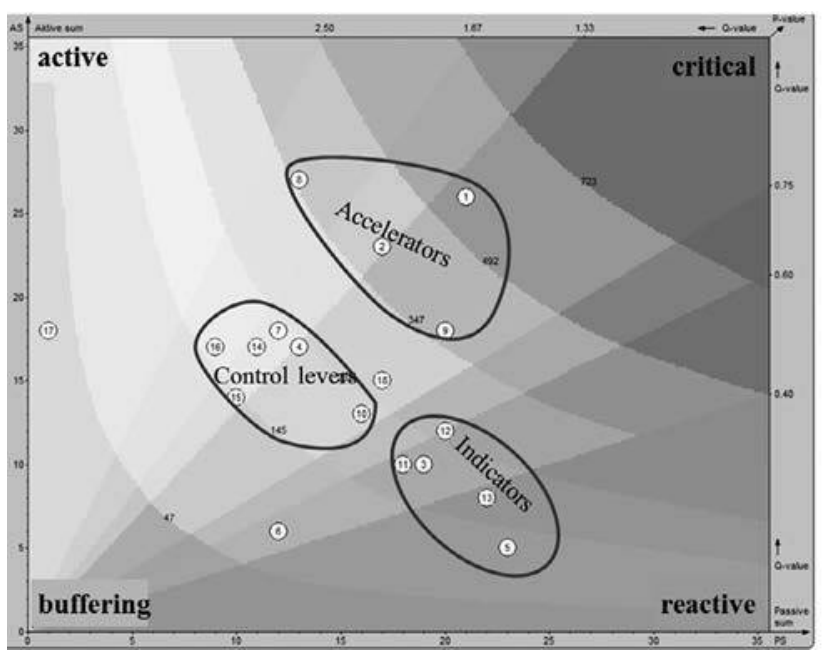

(1) Vision Building

(2) Top-Management Involvement

(3) Partner Assessment

(4) Benefit Concept

(5) Monitoring Concept

(6) IT-Support

(7) Change Concept

(8) Planning Resources

(9) Joint Activities

(10) Training Concept

(11) AÜG Project

(12) Integration Concept

(13) Role Model

(14) Contract I (completeness)

(15) Contract II (limitation)

(16) Asset Specificity

(17) Production Link

(18) Agency Concept

Source: Edited screenshot: Prof. Vester Sensitivity Model ${ }^{\circledR}$

\section{Appendix 5}

Figure AII.

Systemic role of benefit concept

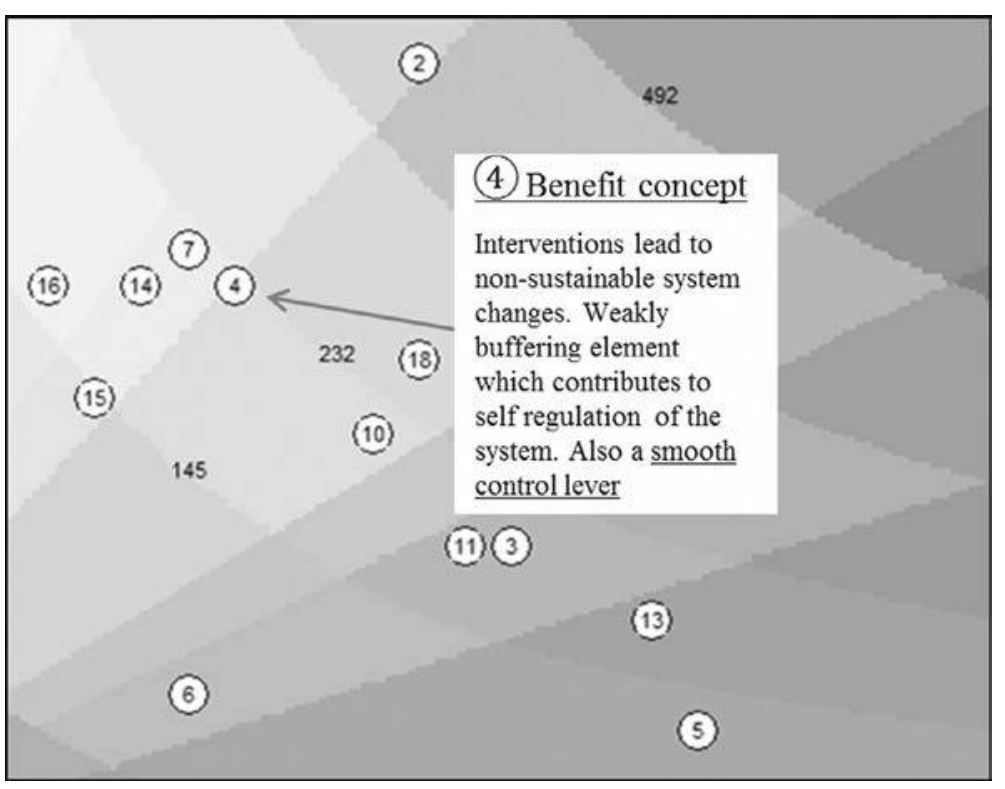

Source: Edited screenshot: Prof. Vester Sensitivity Model ${ }^{\circledR}$ 


\section{Appendix 6}

1. System description The system description mainly encompasses the definition of system elements which sufficiently characterize the system. As a rule of thumb to keep the system manageable there should not be more than 30 elements. An additional check whether the elements reflect the essential characteristics of the system is recommended (Vester, 2007, pp. 211-218). For managers of logistics service provider partnerships the elements identified in this paper may already provide a good basis for their individual approach

2. Interaction analysis of the elements

3. Role determination of the elements
In this step the relation of the elements is examined applying a cross-impact matrix. This step is so easy and convincing that it got widely known and used under the term "paper computer". This means that this step can be performed with the help of only a piece of white paper. Doing so the evaluator has to answer the following question: If element A changes, how strong is the impact on element $\mathrm{B}$ ? The influences between all system elements have a value between 0 and 3. (0 - no impact, 1 - slight impact, 2 medium impact, 3 - strong impact). The direction of the impact, positive or negative does not matter at this stage! To ensure validity, this assessment should be performed by at least two, recommended are three groups/ individuals familiar with the system. The software supports this step by showing where strong discrepancies (differences $\geq 2$ points) between the individuals/groups arise. Where such discrepancies arise a follow-up discussion with all participants is suggested. If the teams do not find a consensus, finally a competent person (probably the project leader) has to take a decision regarding the evaluation

This step is probably the most important for managers who want to understand the interconnectedness (feedback potential) of a distinct system. Different from other techniques which require a high level of mathematical and software skills and the corresponding software (e.g. SEM) this analysis can be performed basically by everybody after a brief introduction on a simple sheet of paper. It becomes even easier when it is executed with help of the software but this is not a necessary requirement at this stage. This step identifies the levers and the indicators within each system. The software provides 50 distinct allocation possibilities. For the practitioner it is valuable to identify clusters of elements which represent the control levers, accelerators and indicators to understand the "genetics" of the system. For managers of logistics service provider partnerships the results of this research may also be a first indication where to look at when thinking in performance management of a distinct partnership (Appendix 4)

\section{Partner management}

261

Table AIV.

Step-by-step guideline for application of

Prof. Vester Sensitivity Model $^{\circledR}$

\begin{abstract}
About the author
Uwe Zybell (Dipl.-Ing., Technische Universitaet Berlin) is a $\mathrm{PhD}$ candidate in Logistics at the Kuehne-Foundation Center of International Logistics Networks at Technische Universitaet Berlin, Germany. His research interests include partner management between customers and logistics service providers and corresponding cooperation management capabilities. His research has been published in one management study and has been presented at international conferences. Uwe Zybell can be contacted at: uwe.zybell@campus.tu-berlin.de
\end{abstract}

\footnotetext{
To purchase reprints of this article please e-mail: reprints@emeraldinsight.com
} Or visit our web site for further details: www.emeraldinsight.com/reprints 


\section{This article has been cited by:}

1. Benjamin Guertler, Stefan Spinler. 2015. When does operational risk cause supply chain enterprises to tip? A simulation of intra-organizational dynamics. Omega 57, 54-69. [Crossref]

2. Kostas Selviaridis, Finn Wynstra. 2015. Performance-based contracting: a literature review and future research directions. International Journal of Production Research 53:12, 3505-3540. [Crossref]

3. Benjamin Guertler, Stefan Spinler. 2015. Supply risk interrelationships and the derivation of key supply risk indicators. Technological Forecasting and Social Change 92, 224-236. [Crossref]

4. André de Waal, Robert Goedegebuure, Eveline Hinfelaar. 2015. Developing a scale for measuring high performance partnerships. Journal of Strategy and Management 8:1, 87-108. [Abstract] [Full Text] [PDF]

5. Donna F. Davis, Wesley Friske. 2013. The Role of Public-Private Partnerships in Facilitating CrossBorder Logistics: A Case Study at the U.S./Canadian Border. Journal of Business Logistics 34:4, 347-359. [Crossref] 